\title{
التوسل بين المشروع وغير المشروع " شبهات وردود" \\ Entreat Between Lawful and Unlawful \\ Suspicions and Responses
}

\author{
كهِ إعداد الباحث \\ محمد احمد حمد الشطي \\ Mohammed Ahmed Hamad Al Shatti \\ مُعلم تربية إسلامية ، وزارة التربية ، الكويت \\ alshatti-m@hotmail.com
}




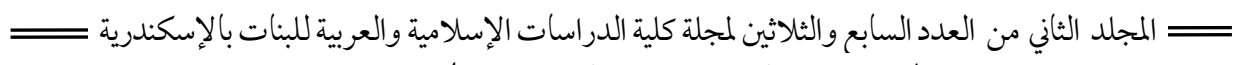

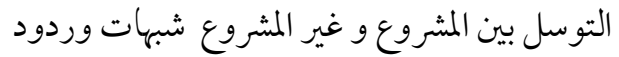


قسم التربية الإسلامية ، وزارة التربية ، الكويت.

\section{alshatti-m@hotmail.com : البريد الاكتروني}

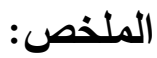

يتعلق الكثير من العوام بالتوسل الغير مشروع، وخاصة التوسل بالنبي صلى الله عليه

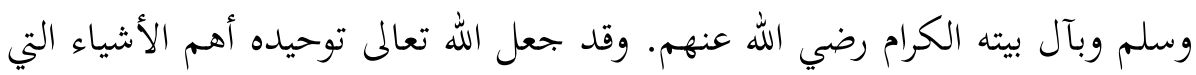

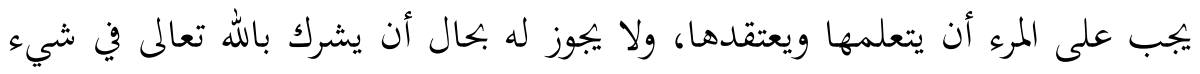

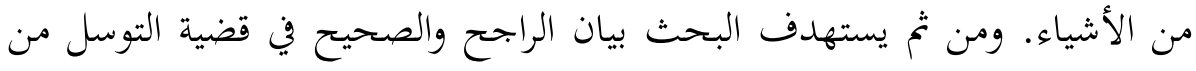

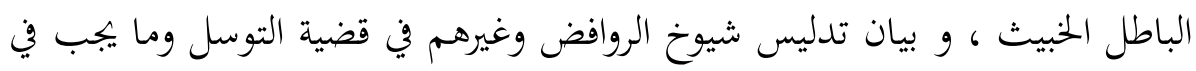

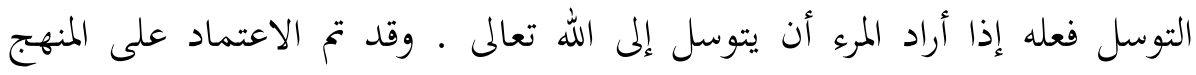

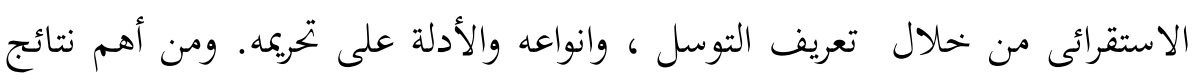

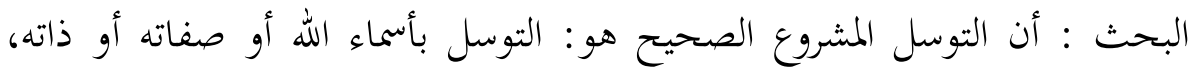

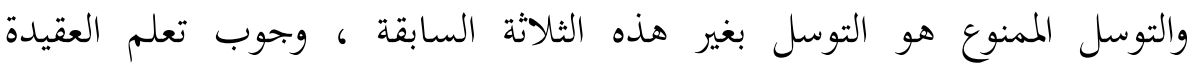
الصحيحة حتى لا يقع المرء المسلم في الشرك وهو لا يدري لغني

الكلمات المفتاحية : التوسل - الثبهات - مسائل التوسل - التوسل فى القرأن

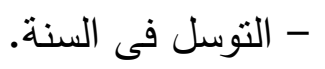




\section{Entreat Between Lawful and Unlawful}

\section{Suspicions and Responses}

Mohammed Ahmed Hamad Al Shatti

Islamic Education Teacher, Ministry of Education, Kuwait.

E-Mail : alshatti-m@hotmail.com

\section{Abstract:}

Many people relate to forbidden begging especially entreating the Prophet (PBUH) and his esteemed household, may Allah be pleased with them . God has made his monotheism the most important thing that a person must learn and believe it is not permissible for him under any circumstances to associate God with any of the things. The research aims to clarify the most correct and correct in the case of begging from a malicious falsehood and a statement of the deception of the Rejections Sheikhs and others in the case of entreat, and what must be done in entreating if a person wants to beg to Allah. The research relied on the historical descriptive method with regard to Definition of entreat and its types and the evidence that it is forbidden . Among the most important results of the research: that the correct legitimate entreat are to seek the names of God, his attributes or himself . and the forbidden entreat is supplication other than these three previous ones.

Keywords: Entreat - Suspicions - Entreat issues - Entreat in Qur'an - Entreat in Sunnah. 


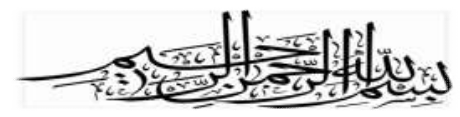

المقدمة:

بسم الله، والحمد لله الذي جعل لنا من العلم نورا نهدي به، والصـلاة والسلام على

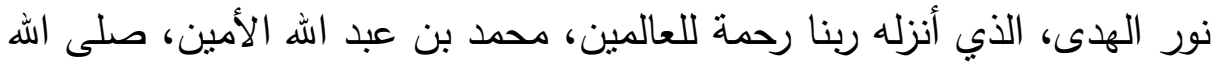
وسلم وبارك عليه وعلى آله وأصحابه، ومن تبعهم بإحسان إلى يوم الدين و

لقد ظهر في الآونة الأخيرة قضية في منتهى الخطورة على الأمة الاسلامية

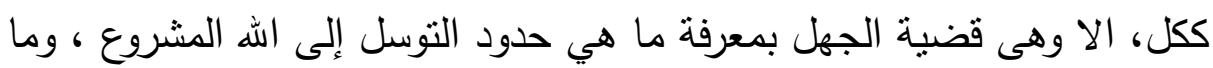
هي حدود التوسل الممنوع ، مما أدى إلى قضايا فتت الأمم الاسلامية مثل تكفير الغير، وقد آن الأوان للأمة أن تعود إلى الكتاب والسنة ، وأن نتمسك بالعقيدة

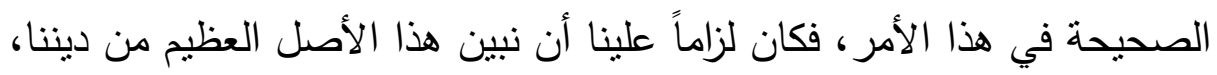
وهو معرفة التوسل المشروع و التوسل الممنوع، لا يحدث شقاق بين المسلمين،

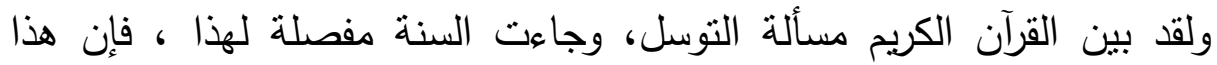

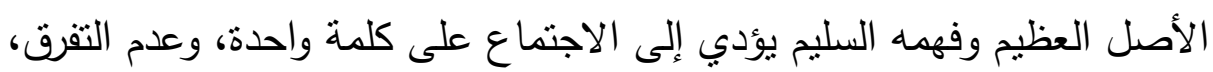
فإن التفرق لا يزيد الأمة إلا وهنًا وضعفًا، ولا تقوم لها قائمة، بل تظل الادل في مؤخرة

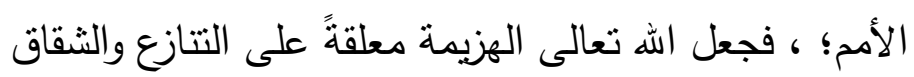

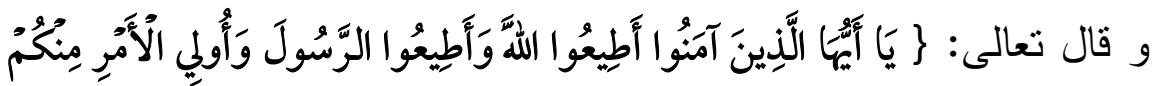

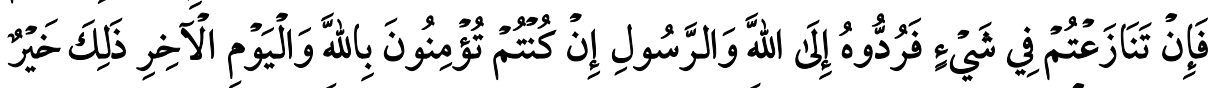

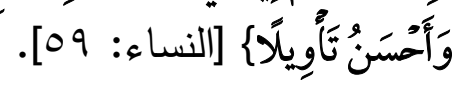
فلا إصلاح ولا خير والأمة تفترق ولا تتجمع، فاله أسال أن يجمعنا على الخير، وأن بفقهنا في ديننا. والله الموفون و المuتعان. 
أهمية الموضوع:

ترتبط أهمية معرفة ضوابط التوسل المشروع و التوسل غير المشروع بقضية التوحيد، فالتوحيد أساس الإيمان، ولقد قال شيخ الإسلام ابن تيمية رحمه الله عن التوحيد هو" دعوة جميع الرسل ومحور جميع الكتب السماوية، وهو صراط الله المستقيم، ولا سبيل إلى الجنة والنجاة من النار إلا به. ومن أجله شرع الجهاد وعلى أساسه ربى الأنبياء أتباعهر"(1)، ولقد أدرك السلف الصالح هذا فعملوا على ولى إلى تبيين الحق من الباطل، اهتداء بكتاب الله وبسنة رسول الله صلى الله عليه وسلم، وكان لزاماً علينا أن نعمل على تبيين حد التوسل المشروع و غير

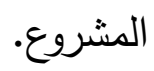

\section{أسباب الموضوع:}

وهناك العديد من الأسباب التي أدت إلى اختياري هذا الموضوع، منها: ا ـ كثرة ظهور الفتن؛ لعدم العلم بضوابط الثرع في قضية معرفة التوسل المشروع والتوسل غير المشروع.

r. أهمية قضية التوسل وارتباطها التام بقضية توحيد الله. r. كثرة ظهور فتتة تكفير المسلمين بعضهم البعض، بسبب الجهل ما يصح وما لا يصح في قضية التوسل.

(1) ينظر : كتاب قاعدة جليلة في التوسل والوسيلة المؤلف: تقي الدين أبو العباس أحمد بن عبد الحليم بن عبد السلام بن عبد الله بن أبي القاسم بن محمد ابن تيمية الحراني الحنبلي

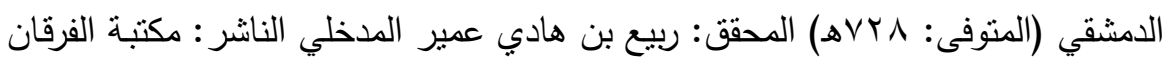

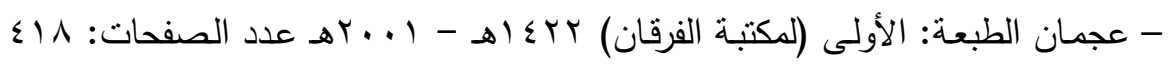
ص م.0. n 


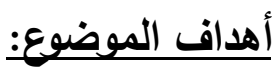

وهنالك العديد من الأهداف لهذا البحث ، وهي: 1 ـ إحياء سنة النبي صلى الله عليه وسلم في التوسل. Y _ معرفة ضوابط التوسل من خلال الكتاب والسنة. r _ حاجة المسلمين إلى هذا الموضوع، فقد ظهرت البدع، وكثرت الفرق، وكثرت الفنن به، فاختلط الحق بالباطل. ع_ حاجة الأمة إليه؛ ليعم الرخاء، ويزيد النعم، فإن الفتن في هذا الأمر كثثرة للغاية. منهج البحث: عملي في البحث: :

أولاً: حرصت على جمع العناصر الأساسية في البحث، وتعربف المصطلحات التي اشتنمل عليها البحث. ثانياً: عملت على تخريج الأحاديث والآثار من مصادرها. ثالثاً: عزوت الأقوال الواردة إلى مصادرها بقر الإمكان. رابعاً: علقت بعض التعليقات في المواضع التي تتطلب التعليق وهي مهمة جداً والحمد لله.

خامساً: قمت بكتابة الآيات والعزو إلى السورة ورقم الآية. سادساً: عملت على ذكر التفسير على الآيات من كتب التفسير • سابعاً:عملت على إعداد فهارس للآيات بترتيب المصحف العثماني، وفهارس للأحاديث أبجديًّا، ترتيب المصادر أبجديًّا. 


\section{خطة البحث:}

تتاولت الحديث في هذه الدراسة في مقدمة، ثلاثة فصول، وخاتمة،

$$
\text { وفهارس وقد قسمتها على النحو التالي ذكره: }
$$

المقدمة: وفيها أهمية البحث وأهدافه، وأسباب اختيار موضوعه، ومنهج البحث، والخطة البحثية التي نتاولت أجزاء البحث من خلالها. المبحث الأول: تعريف الوسيلة والتوسل ، وفيه مطلبان: المطلب الأول: الدلالات اللغوية لمفردات البحث التالية:" الوسيلة _التوسل"

المطلب الثاني: الدلالات الاصطلاحية لمفردات البحث التالية:" التوسل" المبحث الثاني: التوسل بين المشروع و غير المشروع، وفيه: المطلب الأول: حد التوسل المشروع مع ذكر الأدلة من الكتاب والسنة. المطلب الثاني: حد التوسل غير المشروع مع ذكر الأدلة من الكتاب والسنة. المطلب الثالث: شبهات وردود.

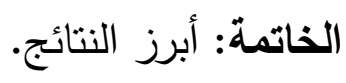

$$
\begin{aligned}
& \text { الفهارس وهي: } \\
& \text { • فهرس الآيات. } \\
& \text { • فهرس الأحاديث. } \\
& \text { • فهرس المراجع. } \\
& \text { • فهرس الموضوعات. }
\end{aligned}
$$




\section{المبحث الأول}

\section{تعريف الوسيلة و التوسل}

المطلب الأول

الدالات اللفوية لمفردات البحث التالية: "الوسيلة- التوسل"

\section{أولاً: الالالة اللفوية لكلمة "لوسبيلة":}

الوسيلة هي: الوصلة والقربى، وجمعها " الوسائل" ،ولقد قال الله تعالى:"

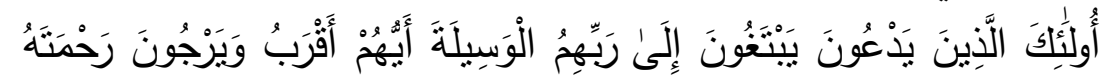

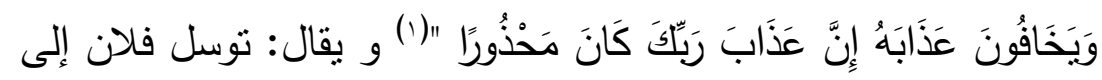

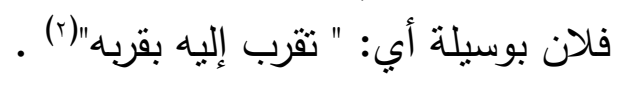

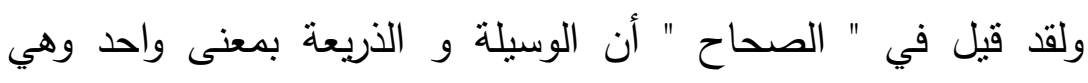
الطريقة، ولقد فرق بين المعنيين أبو هلال العسكري في " فروقه " وقال:

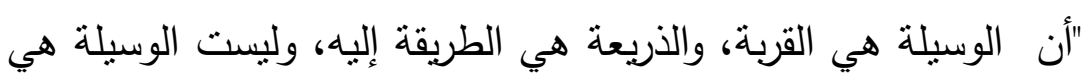

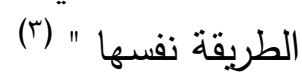

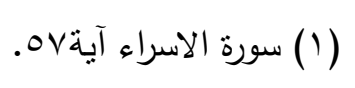

(r) ينظر : تهذيب اللغة المؤلف: محمد بن أحمد بن الأزهري الهروي، أبو منصور (الهتوفى:

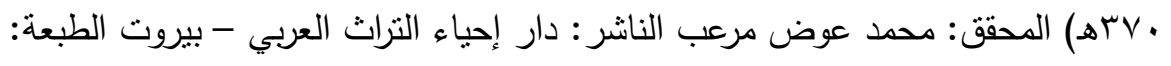

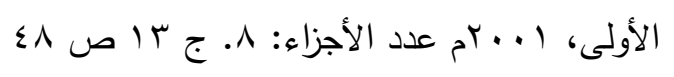

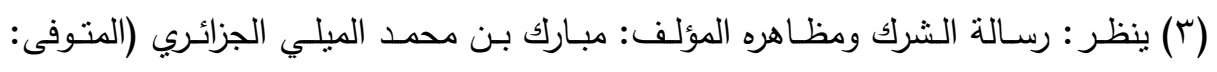

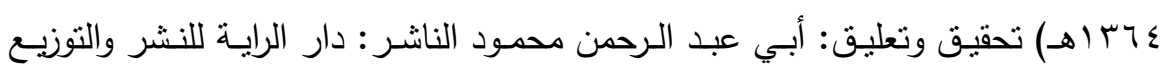

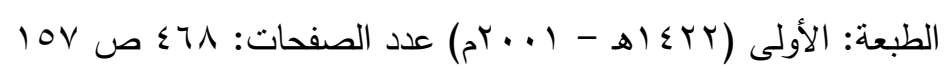


ثثانياً: الالالة اللغوية لكلمة " التوسل":

التوسل من وسل يسل، والتوسل يدل على عمل يقرب إلى الذي توسل إليه، أو

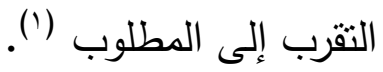

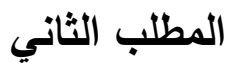

الالالات الاصطلاحية لمفردات البحث التالية:" الوسيلة و التوسل"

أولاً: الدلالة الاصطلاحبة لكلمة "الوسبيلة":

الوسيلة في اصطلاح العلماء هي "القربة،"(r)، وقيل هي: التقرب إلى اله

بطاعته، وبما يرضيه مما شرعه وأذن فيه(").

(1) ينظر : مختار الصحاح الرازي، فصل التاء، مادة [وسيلة]، الناثر : المكتبة العصرية -

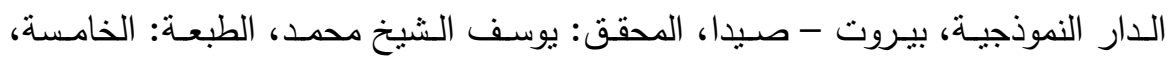

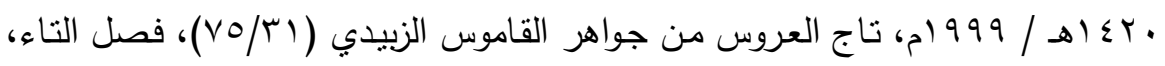

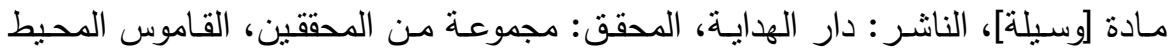

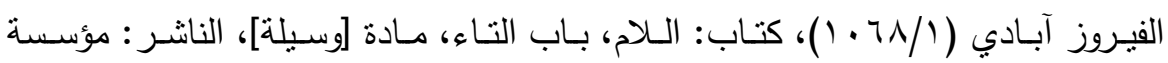

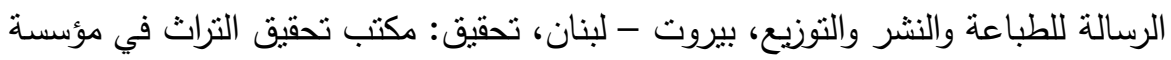

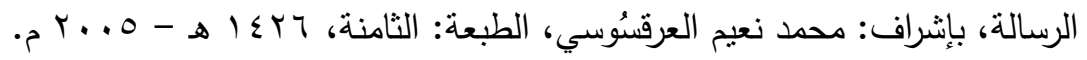

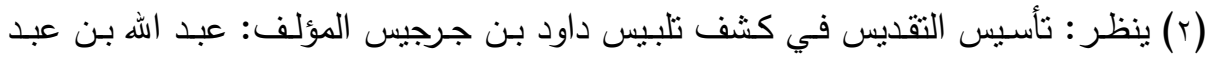

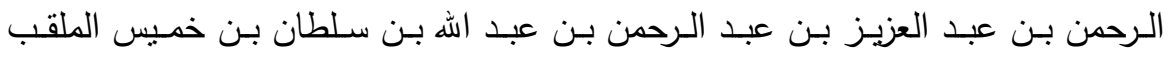

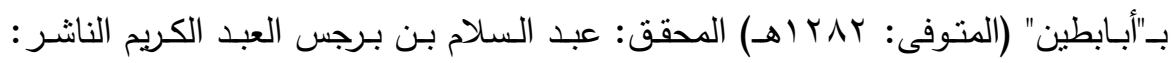

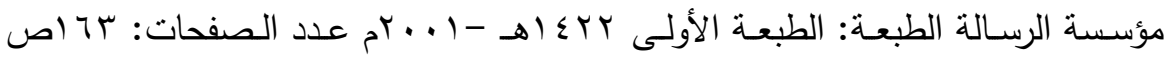
$.1 \leqslant 0$

(r) ينظر : الضياء الشارق في رد شبهات المـاذق المـارق المؤلف: سليمان بن سحمان بن

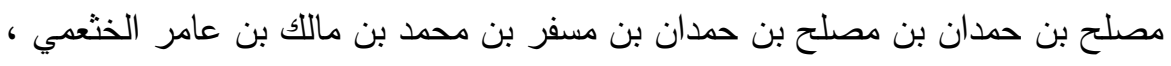

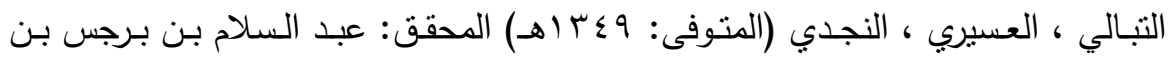

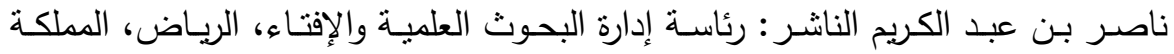

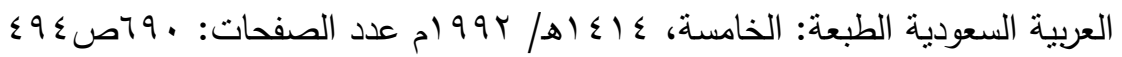




\section{ثانياً: الدلالة الاصطلاحية لكلمة" التوسل":}

التوسل في اصطلاح العلماء هو : طلب القربة إلى لله سبحانه وتعالى، ولقد قال الله تعالى:" يا أيها الذين آمنوا اتقوا الله وابتغوا إليه الوسيلة وجاهدوا في سبيله

لعلكم تقلحون" (1)

فالتوسل هو التوصل والتقرب(؟).

(1)ينظر : كتاب الضياء الشارق في رد شبهات الماذق المارق المؤلف: سليمان بن سحمان

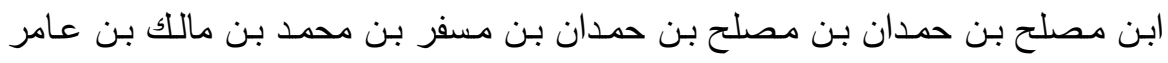

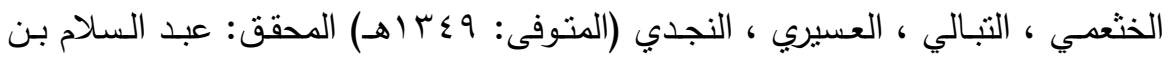

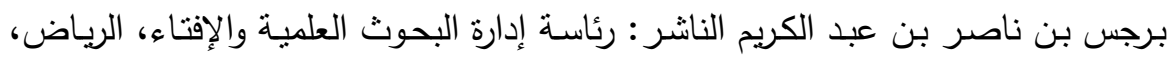

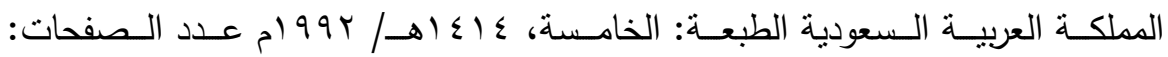

$\leq 9 \leq \operatorname{ciq.~}$

(r)ينظر : جلاء العينين في محاكمة الأحمدين المؤلف: نعمان بن محمود بن عبد اله، أبو

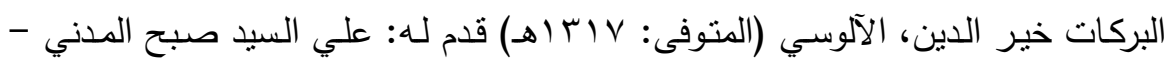

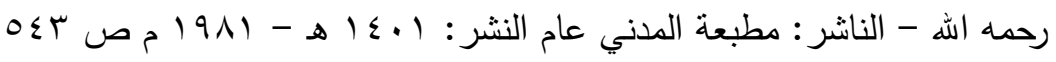

$Y \cdot V=$ 


\title{
المبحث الثاني
}

\section{التوسل بين المشروع والغير مشروع}

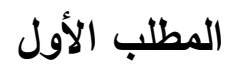

\section{حـ التوسل المشروع مع ذكر الأدلة من الكتاب واللسنة}

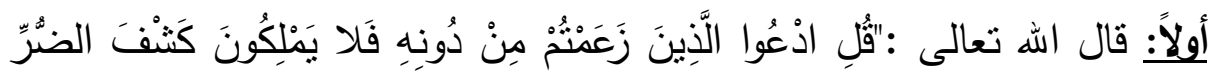

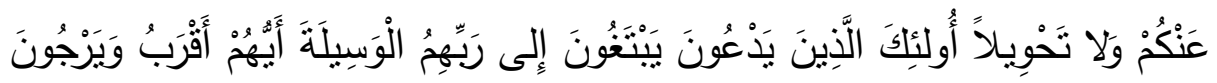

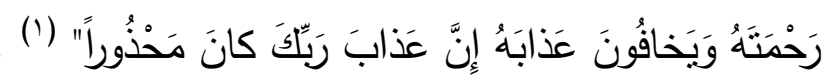
قال الإمام الرازي " اعلم أن المقصود من هذه الآية الرد على المشركين لأنهم كانوا يقولون "ليس لنا أهلية

أن نشتغل بعبادة اله تعالى فنعبد المقربين من عباد الله وهم الملائكة ، ولقد رد

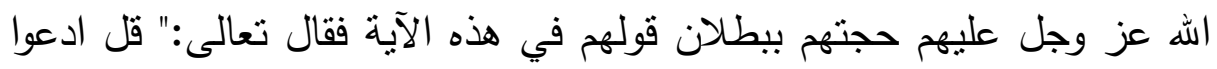

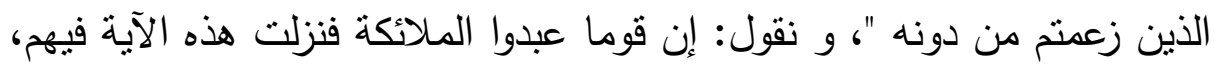

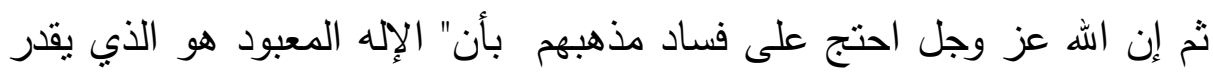

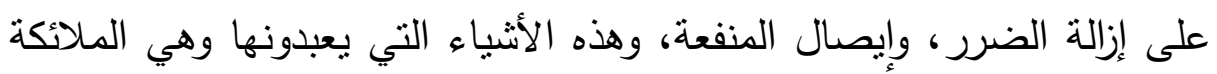
والجن والمسيح وعزيز لا يقدرون على كثف الضر ولا على تحصيل النفع (؟).

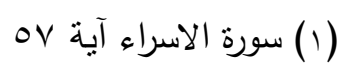

(r) ينظر : كتاب: مفاتيح الغيب = التفسير الكبير المؤلف: أبو عبد الله محمد بن عمر بن الحسن بـن الحسين التيمي الـرازي الملقب بفخر الدين الرازي خطيب الري (المتوفى:

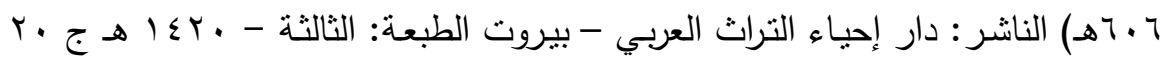




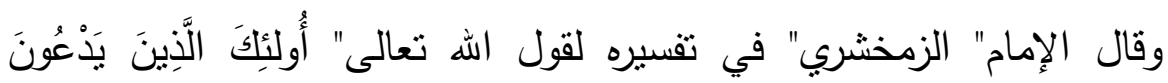

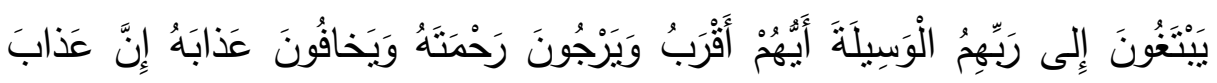

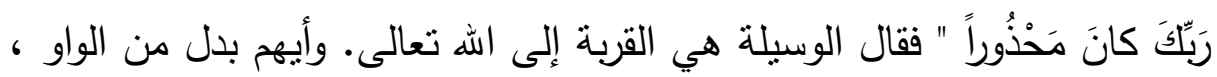

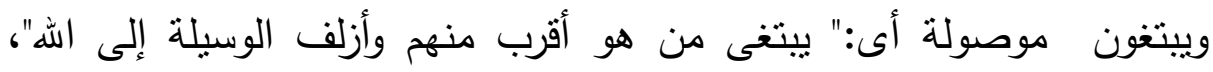

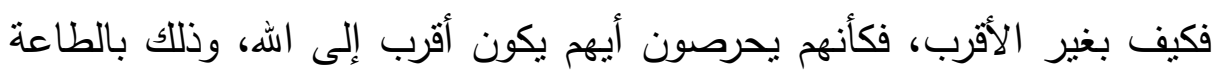

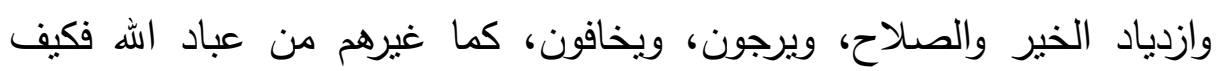
يزعمون أنهم آلهةب؟

إن عذاب ربك كان حقيقا بأن يحذره كل أحد من ملك مقرب ونبى مرسل، فضلا عن غيرهم" (1) فئ عان

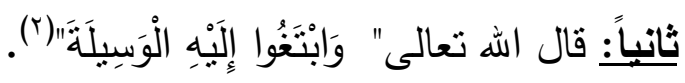
قال الإمام " الرازي" في تفسير الآية الكريمة وفي الآية مسائل منها:

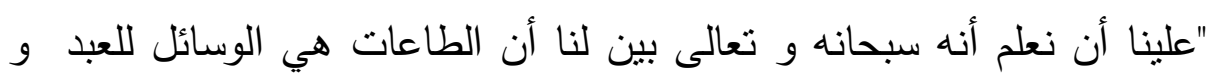
تقربه إلى الرب، فكونوا متوسلين إلى الله بطاعات الله، و ليكن مفاخرتكم بأعمالكم لا بشرف آبائكم وأسلافكم، فاتقوا الله وابتغوا إليه الوسيلة.

(1) ينظر : كتاب الكثاف عن حقائق غوامض التنزيل (مع الكتاب حاشية (الانتصاف فيما

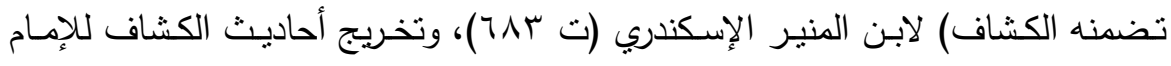

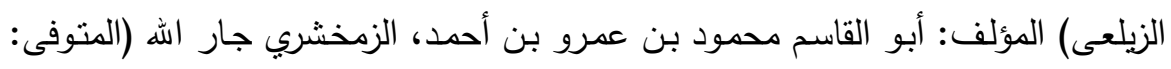

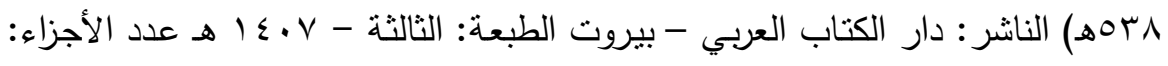

$$
\text { أجr }
$$

(Y) سورة المائدة آية 0. 
و اعلم أن مجامع التكليف محصورة في نوعين لا ثالث لهما: أحدهما: ترك المنهيات، وإليه الإشارة بقوله اتقوا الله وثانيهما: فعل المأمورات، وإليه الإشارة

بقوله تعالى:" وابتغوا إليه الوسيلة" (1)

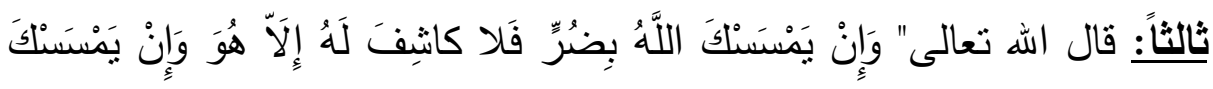

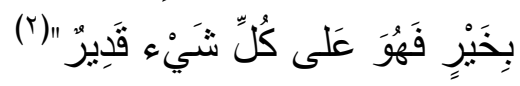

\section{قال الإمام "الثرازي" إن في الآية مسائل منها:}

-" أنه لا يجوز للعاقل أن يتخذ غير الله ولياً ، وأن الله سبحانه تعالى هو القادر على دفع المضار قليلها وكثيرها وأنها لا بدفعها إلا باله، والخيرات لا لهات يحصل قليلها وكثيرها إلا باله"

فإن قيل: قد نرى أن الإنسان يدفع المضار عن نفسه بماله وبأعوانه وأنصاره، وقد يحصل الخير لله بكسب نفسه وبإعانة غيره.

كان الجواب:" أن كل فعل يصدر عن الإنسان فإنما يصدر عنه إذا دعاه الداعي إليه لأن الفعل بدون الداعي محال، وحصول تلاك الداعية ليس إلا من الله تعالى، فيكون دفع الضر او جلب المصلحة من الله تعالى "(r).

(1) ينظر : كتاب مفاتيح الغيب = التفسير الكبير المؤلف: أبو عبد الهه محمد بن عمر بن الحسن بـن الحسين التيمسي الـرازي الملقب بفخر الدين الرازي خطيب الري (المتوفى:

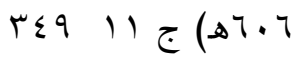

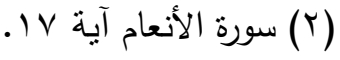

(r) ينظر : كتاب مفاتيح الغيب = التفسير الكبير المؤلف: أبو عبد اله محمد بن عمر بن الحسن بـن الحسين التيمسي الـرازي الملقب بفخر الدين الرازي خطيب الري (المتوفى:

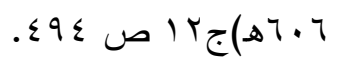


أولاً: من وسائل التوسل المشروع إلى الله تعالى" التوسل إلى الله بالعمل

فالتوسل و التقرب إلى اله تعالى بالعمل الصالح من أعظم أنواع التوسل له ، فقد ورد عن رسول الله صلى الله عليه وسلم أنه قال: " انطلق ثلاثة رهط ممن كان قبلكم حتى أووا المبيت إلى غار ، فدخلوه فانحدرت صخرة من الجبل، فسدت

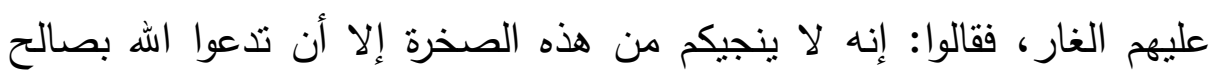

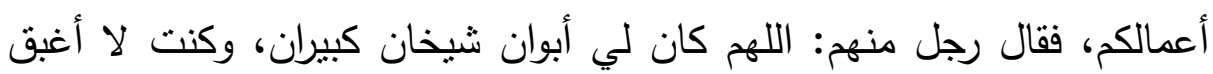

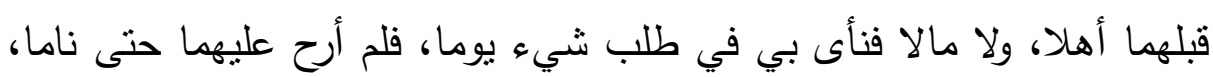
فحلبت لهما غبوقهما، فوجدتهما نائمين وكرهت أن أغبق قبلهما أهلا أو مالا، فلبثت والقدح على يدي، أنتظر استيقاظهما حتى برق الفجر، فاستنظظا، فثربا غبوقهما، اللهم إن كنت فعلت ذللك ابتغاء وجهاك، ففرج عنا ما نحن فيه من هذه الصخرة، فانفرجت شيئا لا بستطيعون الخروج "، قال النبي صلى اله عليه وسلم: " وقال الآخر: اللهم كانت لي بنت عم، كانت أحب الناس إلي، فأردتها عن نفسها، فامتتعت مني حتى ألمت بها سنة من السنين، فجاءنتي، فأعطيتها عشرين ومائة دينار على أن تخلي بيني وبين نفسها، ففعلت حتى إذا قدرت عليها، قالت: لا أحل للك أن تفض الخانم إلا بحقه، فتحرجت من الوقوع عليها، فانصرفت عنها وهي أحب الناس إلي، وتركت الذهب الذي أعطيتها، اللهم إن كنت فعلت ابتغاء وجهاك، فافرج عنا ما نحن فيه، فانفرجت الصخرة غير أنهر لا 
يستطيعون الخروج منها "، قال النبي صلى الله عليه وسلم: " وقال الثالث: اللهم إني استأجرت أجراء، فأعطيتهم أجرهم غير رجل واحد ترك الذي له وذهب، فثمرت أجره حتى كثرت منه الأموال، فجاعني بعد حين فقال: يا عبد الله أد إلي أجري، فقلت له: كل ما ترى من أجرك من الإبل والبقر والغنم والرقيق، فقال: يا عبد الهه لا تستهزئ بي، فقلت: إني لا أستهزئ بك، فأخذه كله، فاستاقه، فلم يترك منه شيئا، اللهم فإن كنت فعلت ذلك ابتغاء وجهك، فافرج عنا ما نحن فيه، فانفرجت الصخرة، فخرجوا بمشون " (').

فقد توسل كل واحد من هؤلاء الثلاثة حين حبسوا في الغار بسبب وقوع الصخرة عليه، فكانت الأعمال الصالحة هي نجاتهم عند الله تعالى، فكانت الأعمال الصالحة من الوسائل التي يجوز التوسل بها إلى الله تعالى؛ لأن الأعمال الصالحة إنما يتقرب بها إلى الله تعالى، ولا يتقرب بها إلى غير الله تعالى، وإنما الأصل في الأعمال الصالحة أنها تقرب إلى الله تعالى، ولا تصرف وتكون لغير الله تعالى، إنما يتقرب العبد بها إلى الله تعالى، فكانت سببًا في التوسل بها إلى الله تعالى، فاله تعالى يفرج الكرب ويرفع الهح والغم بسبب الأعمال الصالحة.

(1) منفق عليه: أخرجه البخاري كتاب: الإجارة، باب: من استأجر أجيرا فترك الأجير أجره،

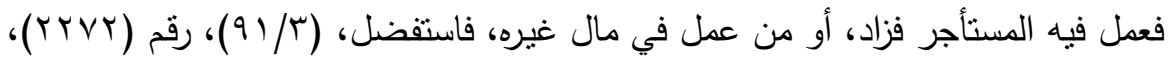

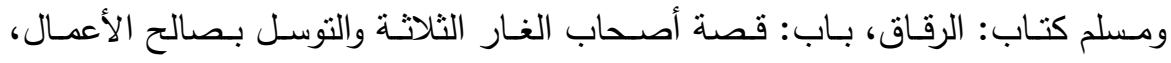

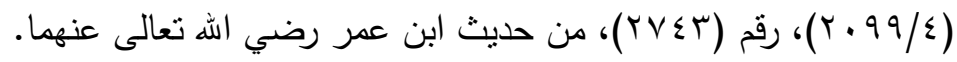


ثانياً: من التوسل المشروع إلحى الله تعالمى "التوسل إلبه بأسمائه و بصفاته":

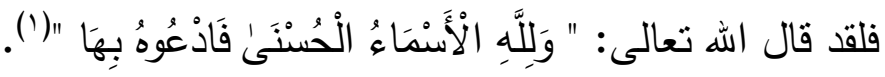

فقال الإمام الرازي في تفسيره: أن الآية دلت على "أنه تعالى حصلت لله أسماء حسنة، وأنه يجب على الإنسان أن يدعو الله بها، وقد أمر الله تعالى عباده كلهم أن يكونوا على إيمان به سبحانه وتعالى، وأن يدعوا غيره وأن لا يتوسلوا بغيره ولا بغير أسمائه الحسنى التي لا يشاركه فيها غيره أحد من الخلق جميعًا، بل كان الأصل على الجميع أن يتوسلوا لله تعالى بذاته وأسمائه وصفاته وكان هذا أمرًا من الله تعالى لجميع الخلق كلهم حتى يكونوا عبادًا لله تعالى (r).

ثالثاً: من التوسل المشروع إلىى الله تعالى "التوسل إلىى الله بعياد الله الصالحين الأحياء منهم ودعائهري:

فعن أنس بن مالك رضي الله عنه أنه قال: " أصابت الناس سنة على عهد رسول الله صلى الله عليه وسلم ، فبينا النبي صلى الله عليه وسلم يخطب في يوم جمعة قام أعرابي ، فقال يا رسول الله: هلك المال وجاع العيال، فادع الله لنا، فرفع يديه وما نرى في السماء قزعة، ف " والذي نفسي بيده، ما وضعها حتى ثار السحاب أمثال الجبال، ثم لم ينزل عن منبره حتى رأيت المطر يتحادر

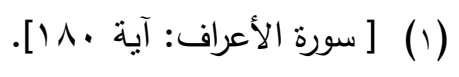

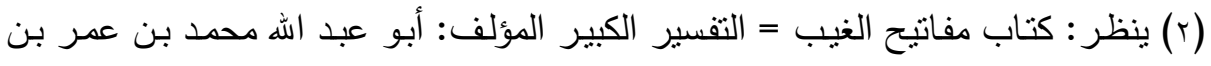
الحسن بـن الحسين التيمي الـرازي الملقب بفخر الدين الـرازي خطيب الري (المتوفى:

$$
\text { (1.7 }
$$


على لحيته صلى الله عليه وسلم، فمطرنا يومنا ذللك، ومن الغد وبعد الغد، والذي يليه، حتى الجمعة الأخرى، وقام ذللك الأعرابي - أوقال: غيره - فقال: يا رسول الله، تهـم البناء وغرق المال، فادع الله لنا، فرفع يديه فقال: „اللهم حوالينا ولا علينا « فما يشير بيده إلى ناحية من السحاب إلا انفرجت، وصارت المدينة منت الجوبة، وسال الوادي قناة شهرا، ولم يجئ أحد من ناحية إلا حدث بالجود (').

\section{وفي الحدبث دلالة على}

أنه يجوز التوسل بالرجل الصالح في قومه بدعائه وطلب الدعاء منه، وأن التوسل برسول الله صلى الله عليه و سلم كان وهو حي صلى الله عليه وسلم وفي حال حياته، وطلب الرجل من النبي صلى الله عليه وسلم أن يسأل الله تعالى أن ينزل عليهم المطر من السماء من أجل أن ينجوا من القحط الذي حلّ عليهم في المدينة، وكان دعاء النبي صلى الله عليه وسلم إنما فيه الإجابة من الله تعالى؛ لأن النبي صلى الله عليه وسلم دعاؤه مستجاب(؟). ولقد ورد عن عمر بن الخطاب رضي الله عنه قال" لما أرادوا الاستسقاء: اللهم

إنا كنا نتوسل إليك بنبينا فتسقينا وإنا نتوسل إليك بعم نبينا فاسقنا فيسقون "(r).

(1) متفق عليه: البخاري كتاب: الجمعة، باب: الاستسقاء في الخطبة يوم الجمعة، (Y/ ( ))، رقم (Tra)، ومسلم كتاب: صلاة الاستسقاء، باب: الدعاء في الاستسقاء، (ץ/乏 (T)، رقم

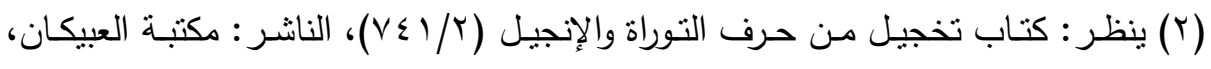
الرياض، المملكة العربية السعودية، المحقق : محمود عبد الرحمن قدح، الطبعة: الأولى،

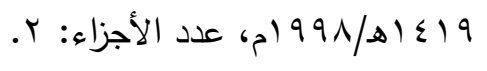

(r)أخرجه البخاري كتاب: أبواب الاستسقاء، باب: سؤال الناس الإمام الاستسقاء إذا قحطوا،

$$
\cdot(1 \cdot 1 \cdot)(r V / r)
$$




\section{وفي الأثر دلالة على أن:}

توسل عمر بن الخطاب رضي اله نعالى عنه وهو الخليفة الثاني من الخلفاء الراندين كان بعم النبي صلى الله عليه وسلم، وكان عم رسول الله صلى الهه

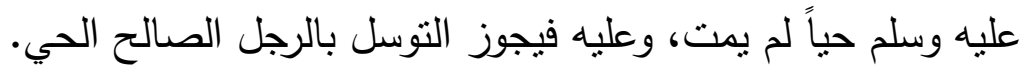

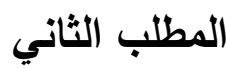

\section{حد التوسل الممنوع مع ذكر الأدلة من الكتاب والسنة.}

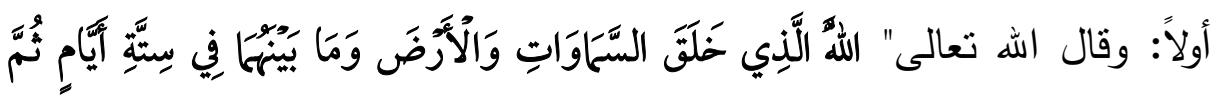

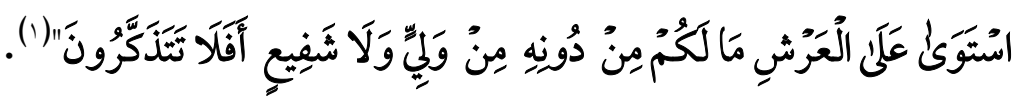
قال الإمام الزمخشري في تفسير الآية الكريمة: " قلت: هو على معنيين،

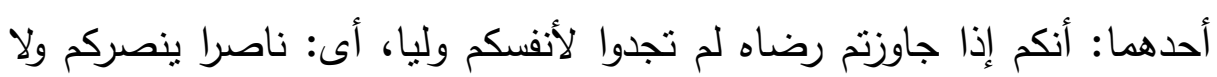

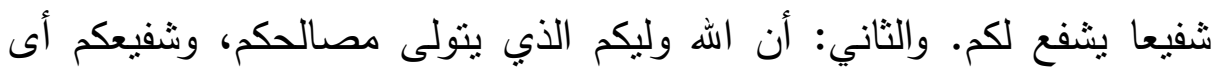

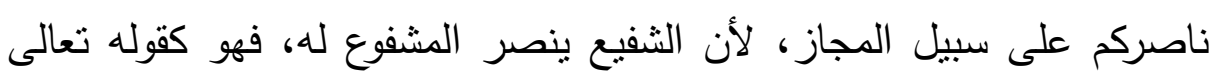
وما لكم من دون الله من ولي ولا نصير فإذا خذلكم لم ييق لكم ولى ولا لاني

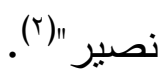

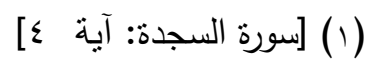

(r) ينظر : كتاب الكشاف عن حقائق غوامض التنزيل مع الكتاب حاثية (الانتصاف فيما

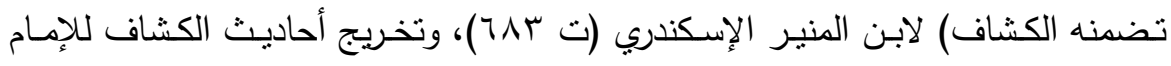
الزيلعى) المؤلف: أبو القاسم محمود بن عمرو بن أحمد، الزمخشري جار الله (المنوفى:

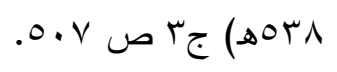




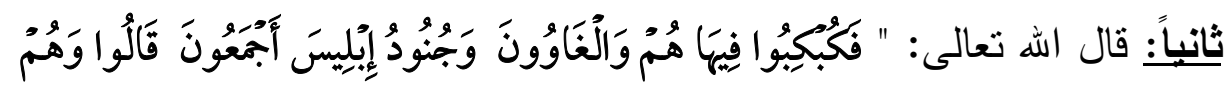

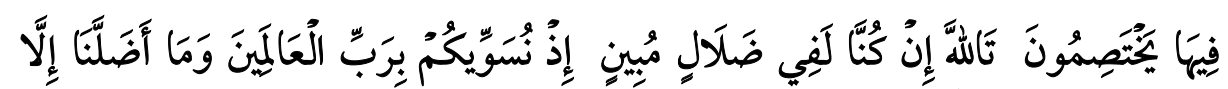

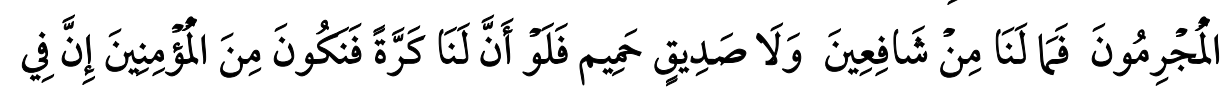

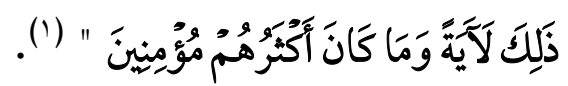

ذكر الإمام الرازي في تفسيره للآية الكريمة :" وما أضلنا إلا المجرمون وأرادوا

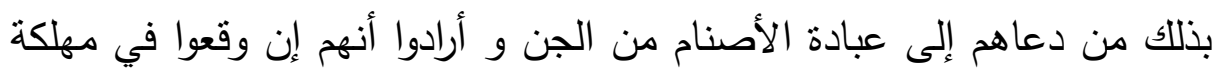

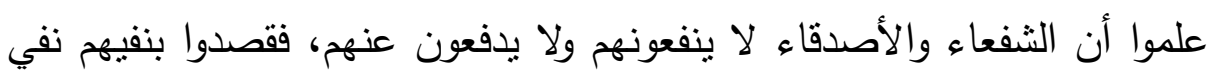
ما تعلق بهم من النفع، لأن مالا ينفع فحكمه حكم المعدوم(r).

وعلى ما سبق قب بيّن الله تعالى لنا أن التوسل غير المشروع على صور منها: أولاً: إن أمر التوسل وطلب الثفاعة من غير الله تعالى؛ لأنه لا يوجد أحد يملك هذا الأمر إلا الله تعالى.

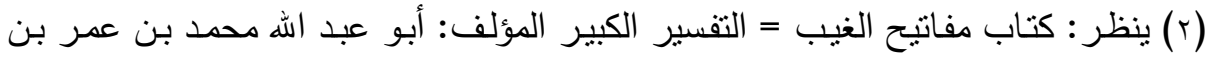

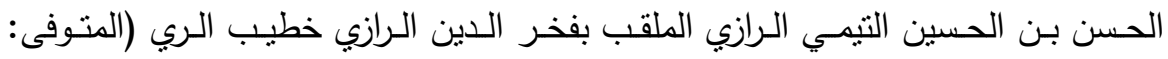

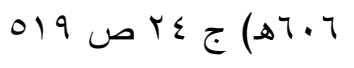


"عن عمر بن الخطاب رضي الله عنه قال" لما أرادوا الاستسقاء: اللهم إنا كنا

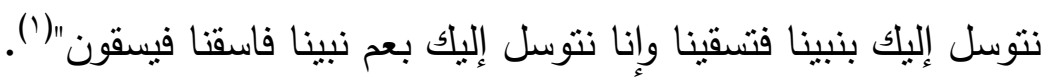
ثانياً: لقد بين الله سبحانه أنه سبحانه وتعالى إنما يجيب ويعطي من يريد من

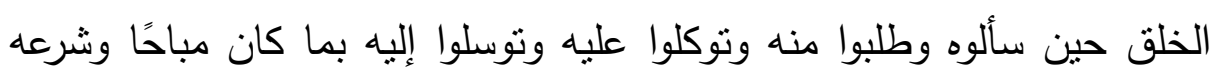

$$
\text { الله تعالى لهم أن ينوسلوا به(r). }
$$

الالديل:

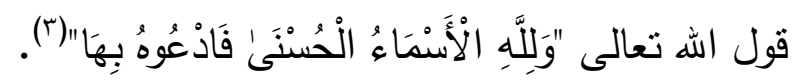

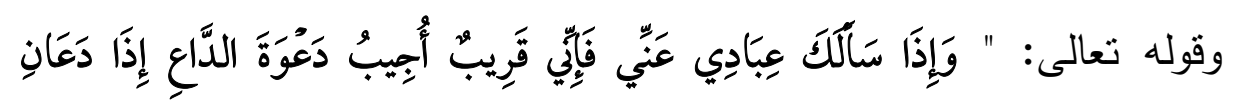

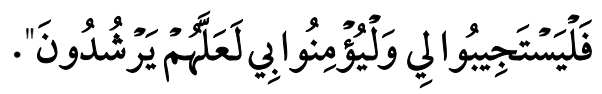
ثالثاً: عدم التوسل لله تعالى بكل شيع محرم، أو شيع لم بشرعه، أو التوسل يغير الله تعالى ويغير أسمائه وصفاته.

الدليل:

رسول الله صلى الله عليه وسلم أنه قال: " انطلق ثلاثة رهط ممن كان قبلكم

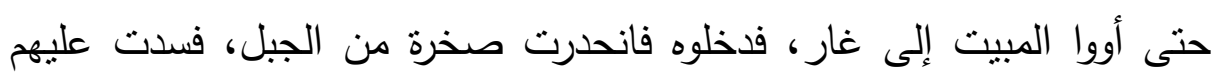

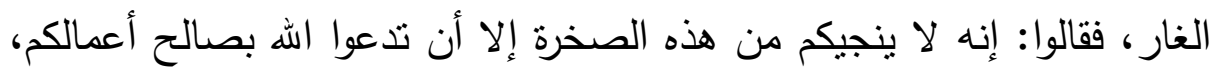

$$
\text { (1) سبق تخريجه (1) بنظيه }
$$

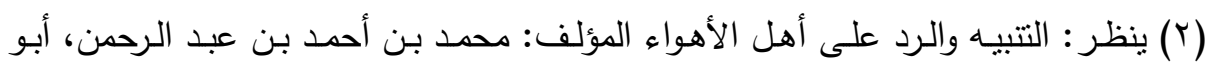

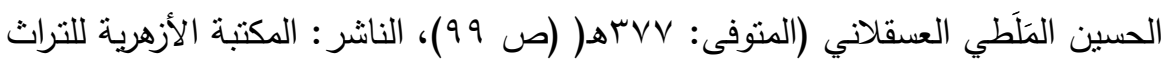

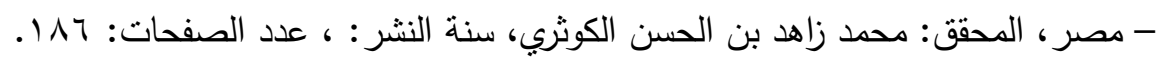

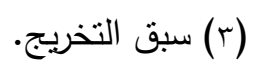


فقال رجل منهم: اللهم كان لي أبوان شيخان كبيران، وكنت لا أغبق قبلهما أهلا،

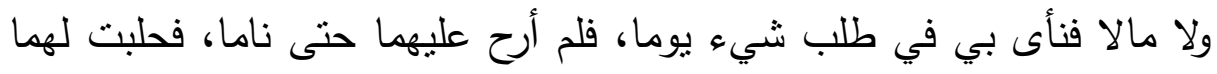

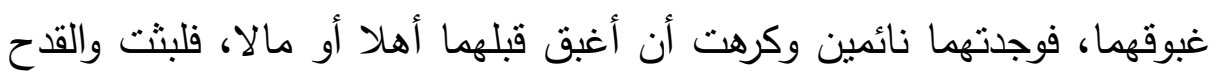

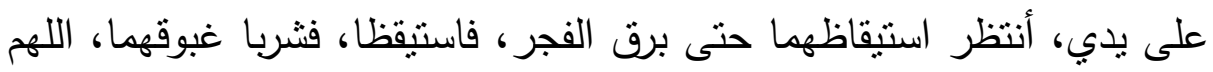

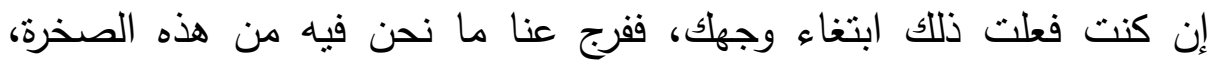

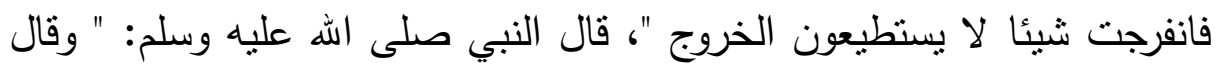

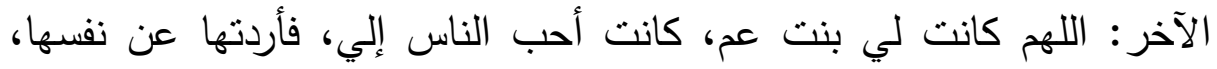
فامتتعت مني حتى ألمت بها سنة من السنين، فجاعتي، فأعطيتها عشرين ومائة

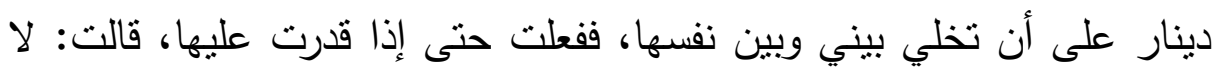

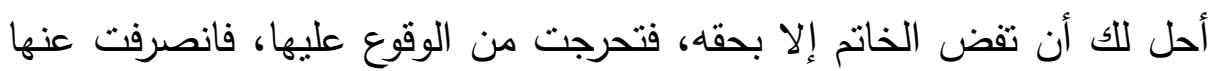

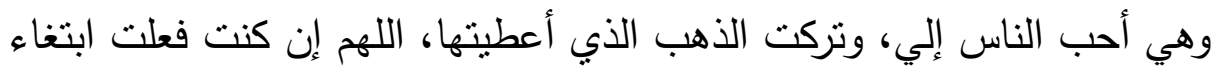

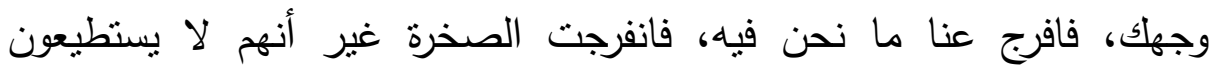

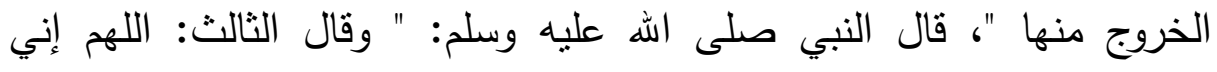

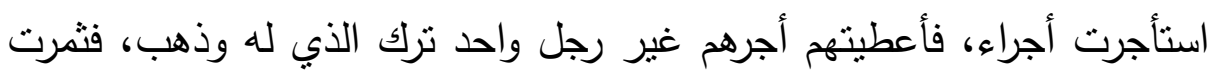

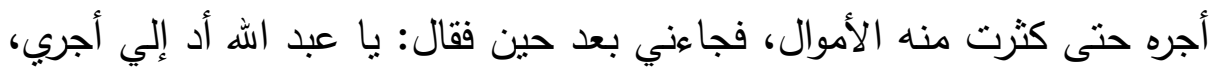

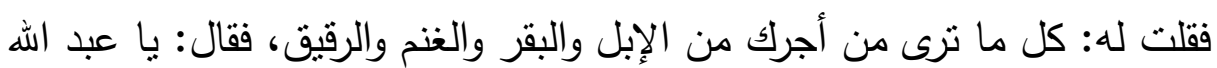

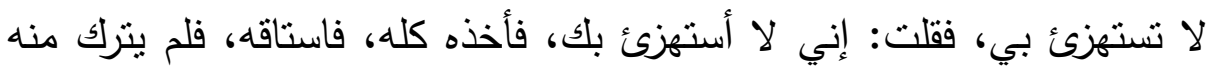

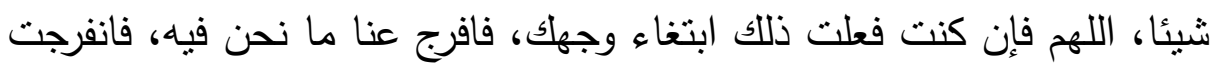

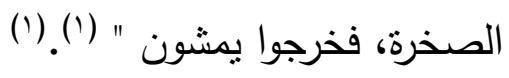

(1) متفق عليه: أخرجه البخاري كتاب: الإجارة، باب: من استأجر أجيرا فترك الأجير أجره،

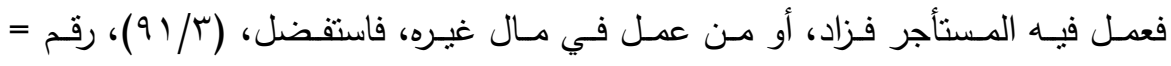

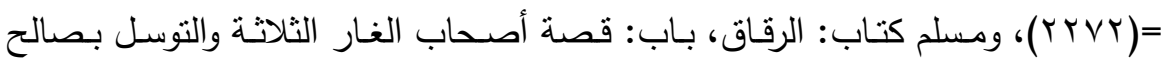

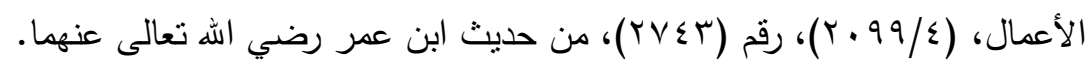


لابعاً: أن التوسيل غير المشروع هو ما كان فيه توسل بذات العبد سواءً النبي

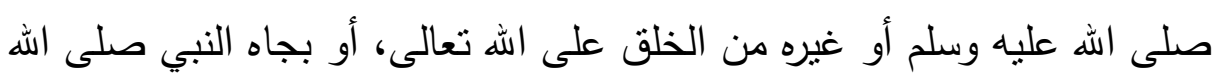

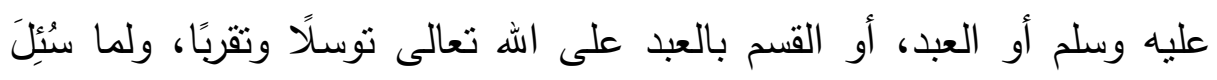

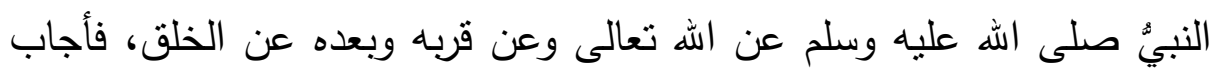

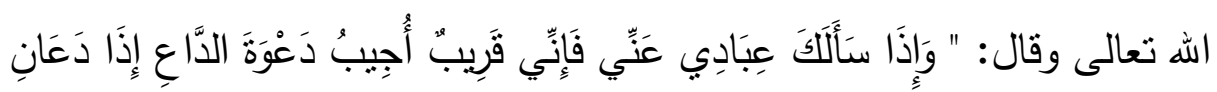

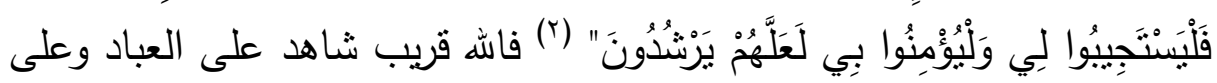

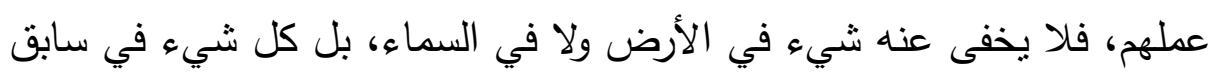

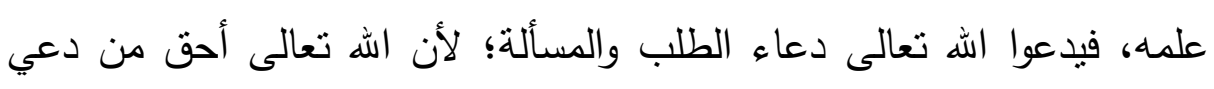
وعبد لا غيره.

\section{الادليل:}

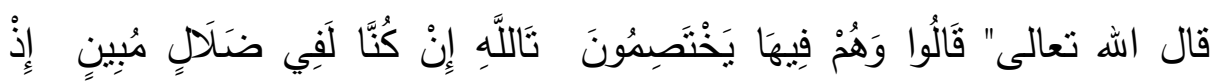

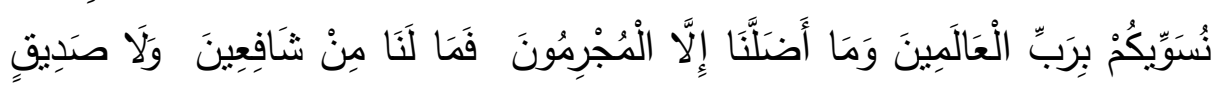

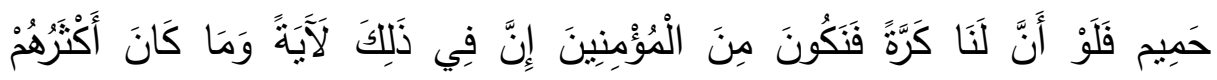

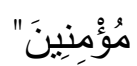


خامساً: أن الله سبحانه لم يجعل بينه ويين أحد من الخلق شيئًا من الأثباءع

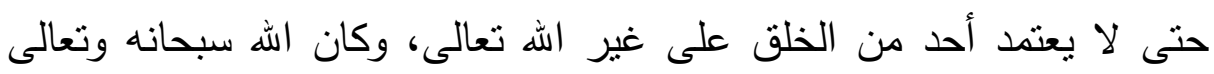

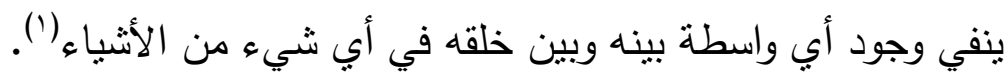

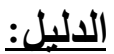

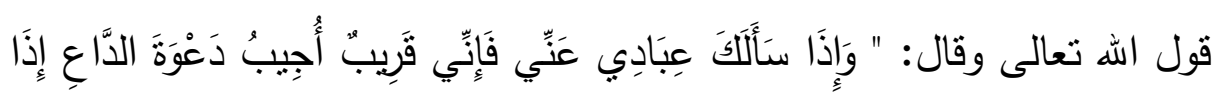

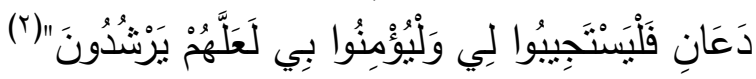

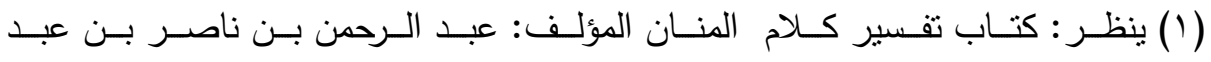

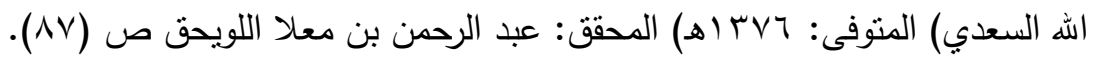

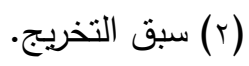




\section{المطلب الثالث}

\section{شبيهات و ردود}

الثبيهة الأولى:

قولهم " إنه يجوز التوسل بالثخص والتوجه به إلى اله تعالى بذاته وليس

بدعائه" (') (1)

\section{وكانت من أدلتهي على تلك الثبهية:}

ما ورد عن عثمان بن حنيف رضي اله عنه " أن رجلاً ضريراً أتى رسول الله

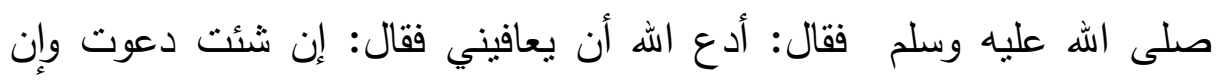

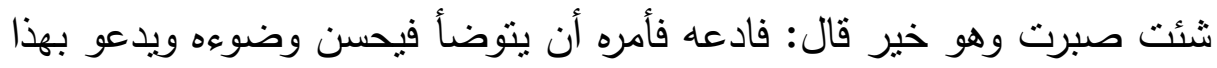

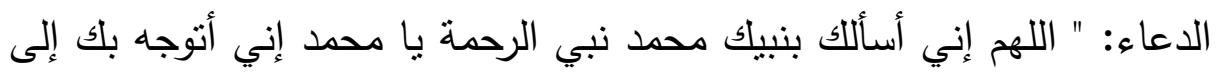

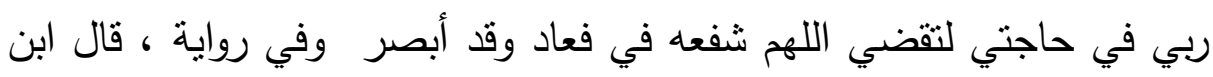

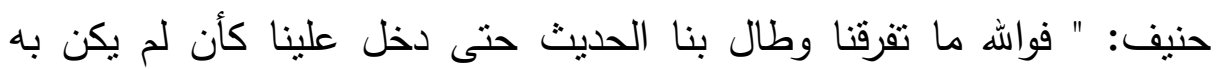

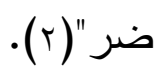

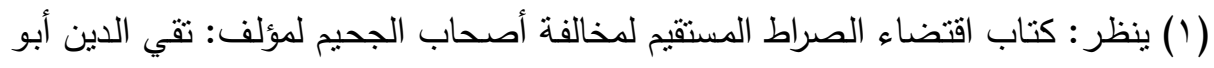

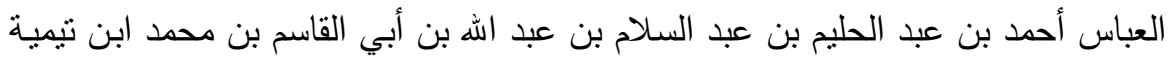

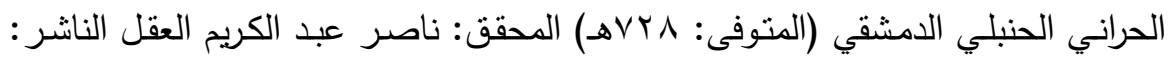

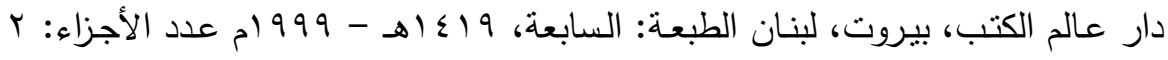

. ( $(r) / r)$

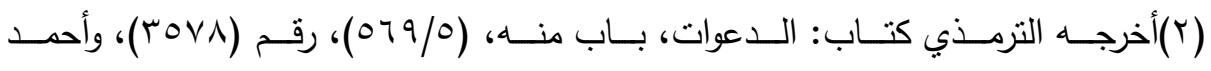

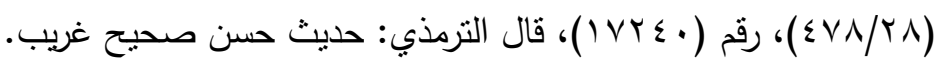




\section{الرد على هذه الشبهة بكون من عدة وجوه:}

\section{الوجه الأول:}

أن الأعمى إنما جاء إلى النبي صلى الله عليه وسلم ليدعو لـه، وذلك قولـه: "أدعُ الله أن يعافيني"، فهو نوسل إلى الله تعالى بلىعائه صلى الله عليه وسلم.

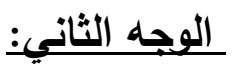

أن لو كان قصد الرجل الضرير التوسل بذات رسول الهه صلى الله عليه وسلم

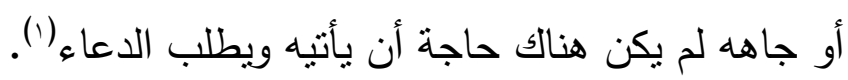

\section{الوجه الثالث: - 2 - الث:}

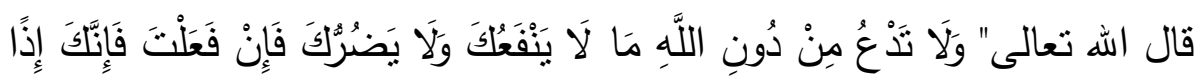

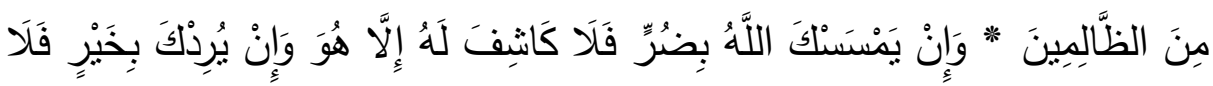

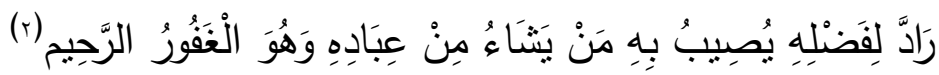

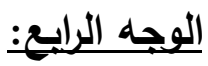

إن قصة عثمان بن حنيف الطبراني لم يصحح القصة، و هذه القصة ضعيفة منكرة، لأمور منها :ضعف حفظ المتفرد بها، ومخالفة هذا المتفرد للتقات.

(1) ينظر : التوسل أنواعه وأحكامه المؤلف: أبو عبد الرحمن محمد ناصر الدين، بن الحاج آلاج

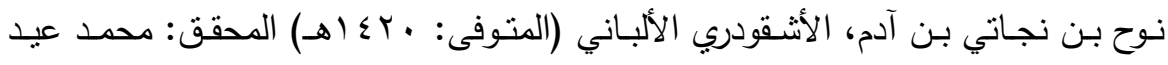

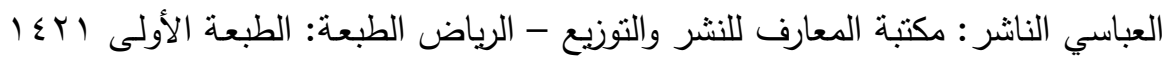

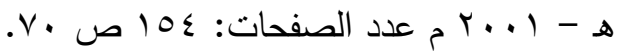

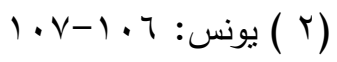


الوجه الخامس:

لقد ورد عن عمر بن الخطاب رضي الله عنه قال" لما أرادوا الاستسقاء: اللهم

إنا كنا نتوسل إليك بنبينا فتسقينا وإنا نتوسل إليك بعم نبينا فاسقنا فيسقون "( ). فكان نوسل عمر بن الخطاب بعم النبي صلى الله عليه و سلم الحي ولم يتوسل أو يستغيث بالنبي صلى الله عليه وسلم وهو ميت حينما حلّ عليهم القحط، ونزل بهم الحاجة إلى الماء والثراب من السماء، فكان الأصل أن يكون هناك توسل بالصالحين الأحياء لا الأموات؛ لأن الأموات لا بملكون لأنفسهم شيئًا من الخير

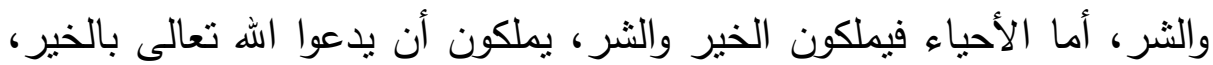
أو أن يعصوا الله تعالى فيقع عليه الثر بسبب أعمالهم، فكان الأحياء يمتازوا عن الأموات بما يملكونه دن الدعاء والعمل الصالح والتوسل إلى الله تعالى (؟). مما يدل على أنه لا يصح التوسل بالأموات ولو كانوا من أنبياء الله تعالى؛ لأن هذا فيه نوع من الثرك الذي لا يرضاه الله تعالى، فالذي يتوسل بالأموات يعلم أن الأموات لا يملكون لأنفسهم شيبًا من الضر والنفع، فكيف يتوسل بهم إلى الله تعالى؟ فكان هذا من الأمور التي لا تصح ولا ترضي الله تعالى، وفيه نسبة

(1) أخرجه البخاري كتاب: أبواب الاستسقاء، باب: سؤال الناس الإمام الاستسقاء إذا قحطوا،

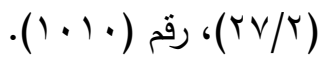

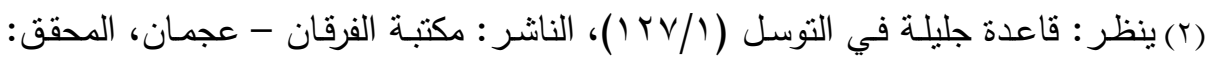

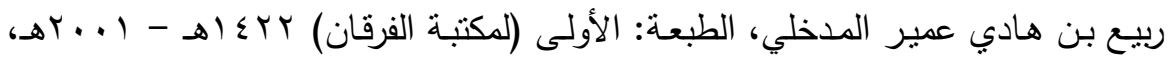




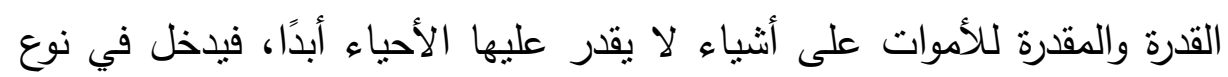

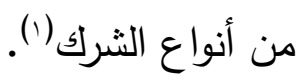

\section{الثبنهة الثانية:}

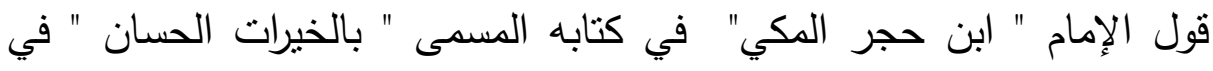
مناقب أبي حنيفة النعمان في الفصل الخامس والعشرين أن الإمام الثافعي أيام

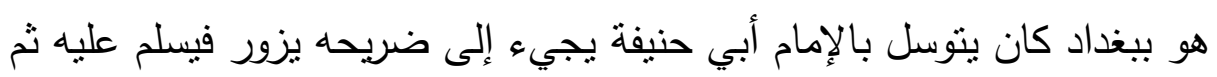
يتوسل إلى الله به في قضاء حاجاته (ץ). ذكر ابن حجر المكي في كتابه المسمى : بالصواعق المحرقة لإخوان الضدلال

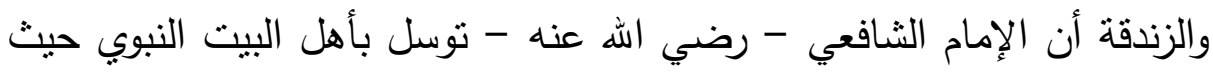
قال : آل النبي ذريعتي أرجو بهم أعطي غداً ... وهم إليه وسيلتي بيدي اليمين

صحيفتي (r)

(1) ينظر :مجموع الفتاوى المؤلف: تقي الدين أبو العباس أحمد بن عبد الحليم بن تيمية

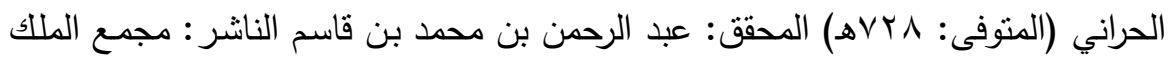

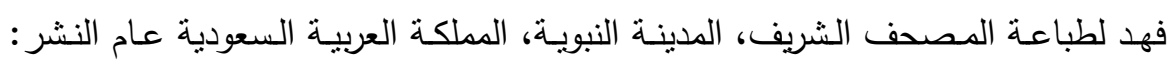

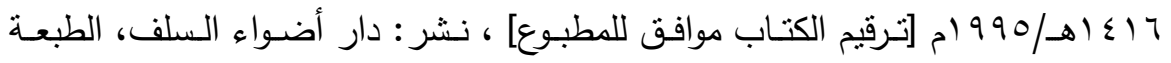

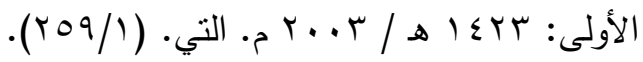

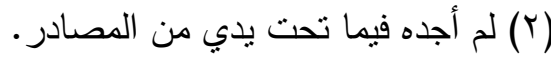

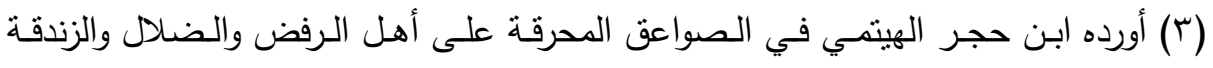

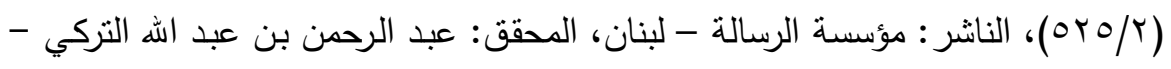

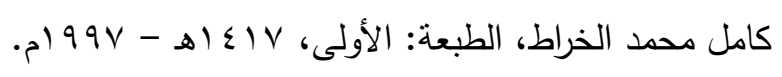




\section{الرد على هذه الثبهة :}

أما أبو حنيفة فالكلام المنسوب إليه كذب؛ لأن الذي نسب إليه من الأحناف غير هذا، ويناقض هذا الكلام تمامًا، فقال أبو حنيفة: لا يجوز لأحد دعاء الله إلا به

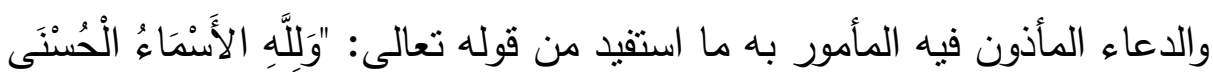

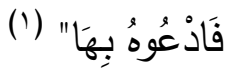

قلت الباحث: وهذا من الكذب المنسوب إلى الثافعي رحمه الله تعالى؛ لأن الهيتمي لم يذكر سندًا إلى الثافعي رحمه الله تعالى، بل ذكره مقطوع، فهذا مما

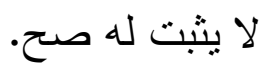

\section{الثبـهة الثالثة:}

جواز التوسل إلى الله تعالى بذات الأثخاص قياساً منهم على التوسل إلى الله تعالى بالأعمال الصالحة.

\section{الرد على هذه الشبهة من عدة أوجه منها:}

الوحه الأول :

أولاً: إن قياس الوسائل التي يتقرب بها العبد إلى الله تعالى قياس في باب العبادات، و القياس في باب العبادات لا يجوز إلا بدليل، والأدلة المذكورة في 
هذه الثبهة تصل لحد الأدلة الموضوعة، ومنها على سبيل المثال لا الحصر: ما ورد عن عثمان بن حنيف رضي الله عنه " أن رجلاً ضريراً أتى رسول الله صلى الله عليه وسلم فقال: أدع الله أن بعافيني فقال: إن شئت دعوت وإن شُت صبرت وهو خير قال: فادعه فأمره أن يتوضأ فيحسن وضوءه ويدعو بهذا الدعاء: " اللهم إني أسأللك بنبيك محمد نبي الرحمة يا محمد إني أتوجه بك إلى لي ربي في حاجتي لتقضي اللهم شفعه في فعاد وقد أبصر وفي رواية ، قال ابن حنيف: " فوالله ما تفرقنا وطال بنا الحديث حتى دخل علينا كأن لم يكن به ضر"(') ، و قصة عثمان بن حنيف أخرجها الطبراني ولم يصحح القصة، و هذه القصة ضعيفة منكرة، لأمور منها :ضعف حفظ المتقرد بها، ومخالفة هذا المتفرد للثقات، والاختلاف من أهل الحديث عليه .

\section{الوجه الثاني :}

إن التوسل المشار إليه في الآيات الكريمة والسنة الثريفة إنما هو التوسل بعمل المتوسل الصالح نفسه، ومن الأدلة على ذلك على سبيل المثال لا الحصر قول

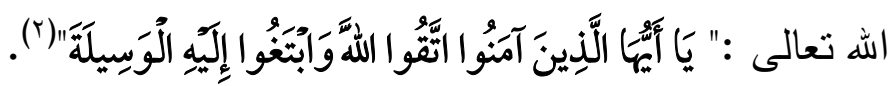

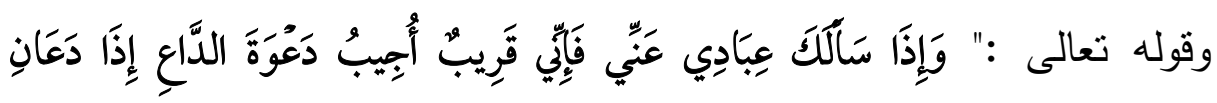

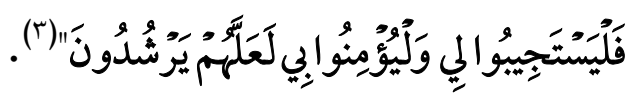

$$
\text { (r) (r) سبق تخريجه. }
$$




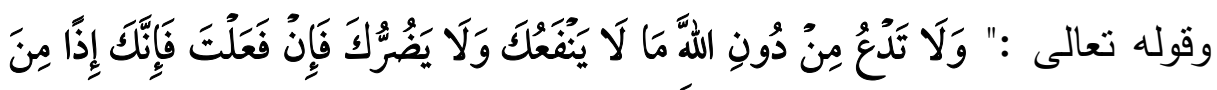

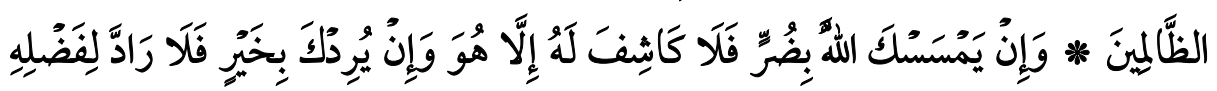

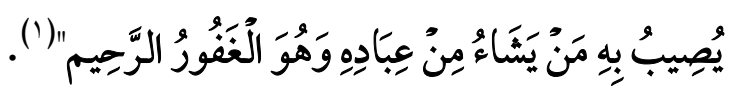

والذي ورد عن رسول اله صلى الله عليه وسلم جواز التقرب إلى اله تعالى بدعائه صلى الله عليه و سلم ودعاءه صلى الله عليه و سلم مستجاب ، فعن

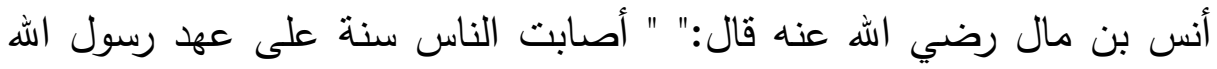
صلى الله عليه وسلم ، فبينا النبي صلى الله عليه وسلم يخطب في يوم جمعة

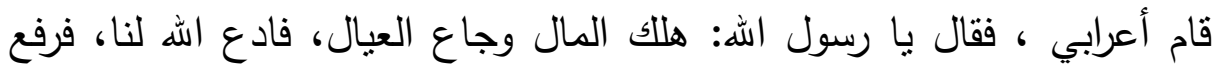
يديه وما نرى في السماء قزعة، ف " والذي نفسي بيده، ما وضعها حتى ثار السحاب أمثال الجبال، ثُ لم ينزل عن منبره حتى رأيت المطر يتحادر على هلى لحيته صلى الله عليه وسلم، فمطرنا يومنا ذللك، ومن الغد وبعد الغد، والذي يليه،

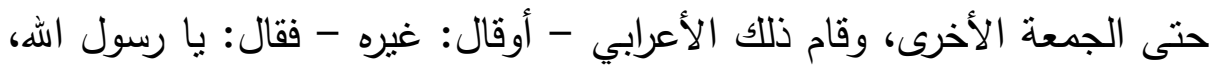

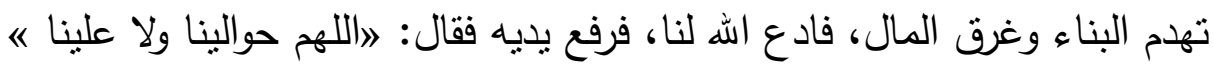

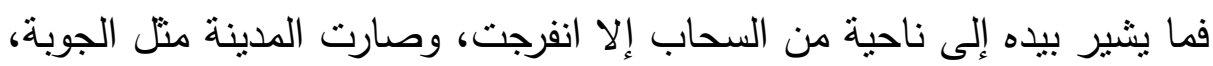

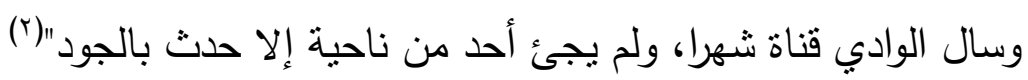

وعلى هذا يكون قد تبين عدم جواز التوسل بالأات، والتوسل المشروع هو

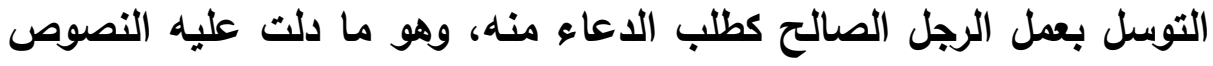

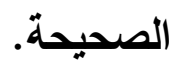




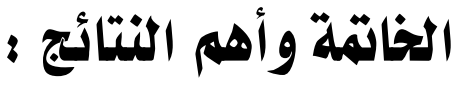

\section{الخاتمة}

في نهاية هذا البحث الذي تعرضنا فيه لموضوع و قضية من أخطر القضايا

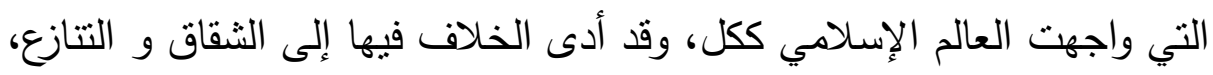
الا وهي قضية التوسل إلى الله بين المشروع و الغير المشروع، وبعض الثبهات

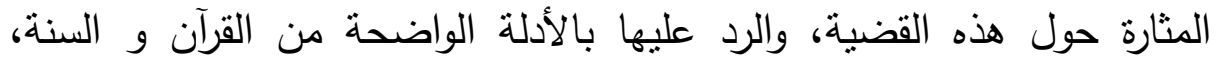

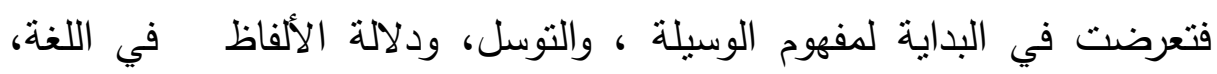

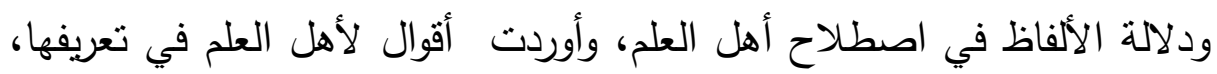

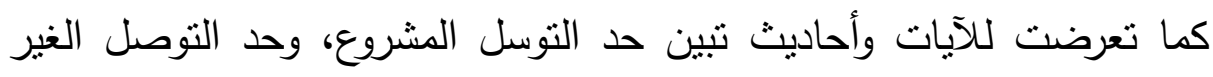

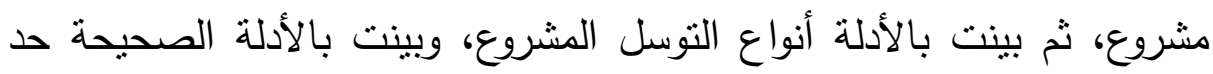

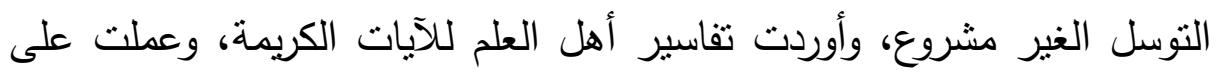

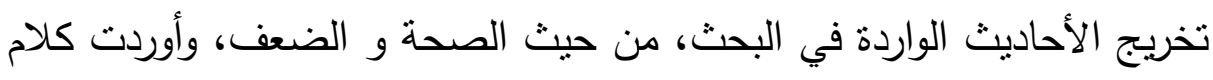

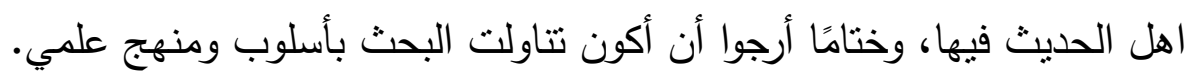

أهم النتائجج: ومن أهم النتائج التي توصلت إليها في هذا البحث:

1. التوسل الششروع الصحيح هو : التوسل لله تعالى و التقرب إليه بأسماء الله

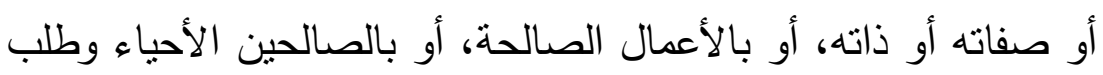

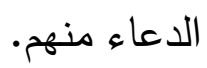
r. التوسل غير المشروع هو: التوسل بغير هذه الثلاثة السابقة أو التوسل

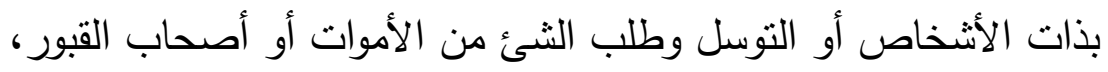

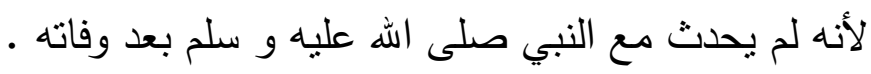


r. وجوب تعلم العقيدة الصحيحة حتى لا يقع المرء المسلم في الثرك وهو

$$
\text { لا بدري. }
$$

ع. درء الدفاسد مقدم على جلب المصالح، فالتبيين و التعليم مقدم على لـى

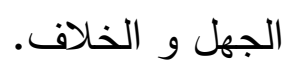

تبين أن قضية التوسل قضية في منتهى الخطورة، و أن الله تعالى شرع التوسل

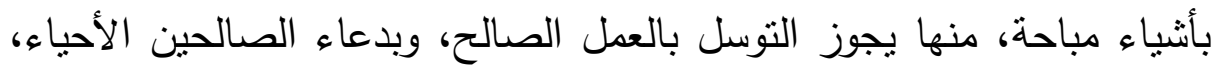

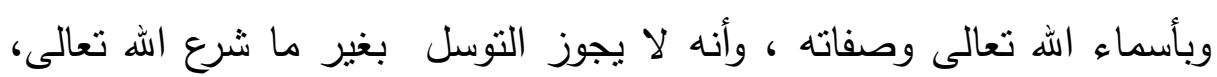

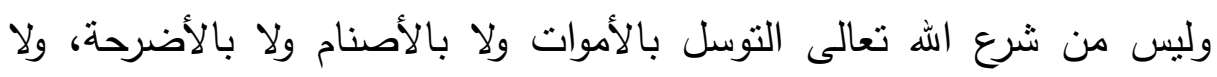
بشخص النبي نفسه صلى اله عليه وسلم بعد موته، بل ؛ لأن اله لا يقبل شريكًا في التوسل، بل شرح دينًا وفرضه على العباد، فيجب على العباد كلهم أن ينقادوا

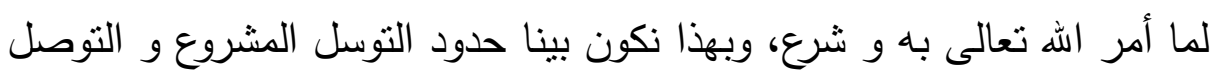

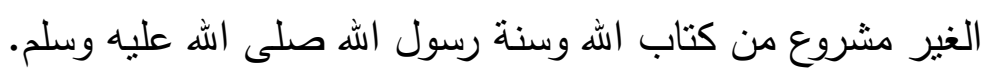
وأنhال الله الفبوله و السباد . 


\section{المراجح}

1. اقتضاء الصراط المستقيم لـخالفة أصحاب الجحيم لمؤلف: تقي الدين

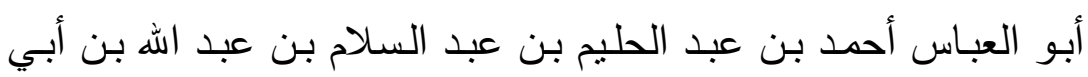

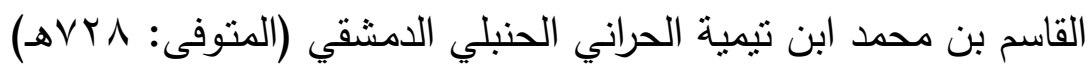

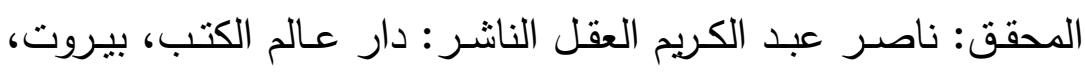

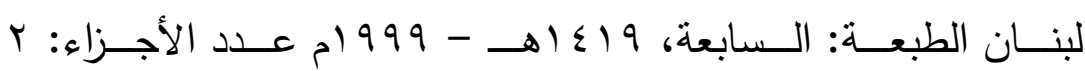
( $($ ( ) $/$ / $)$

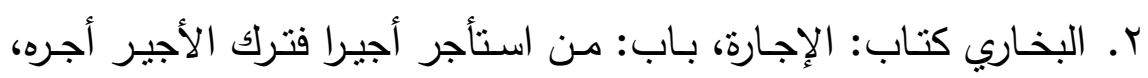

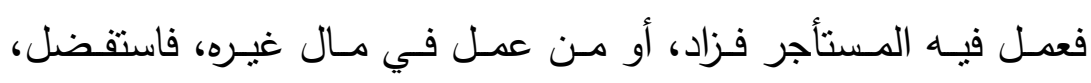

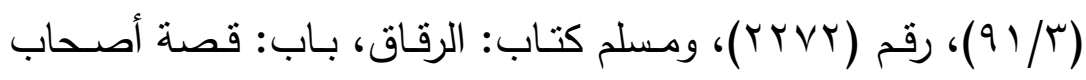

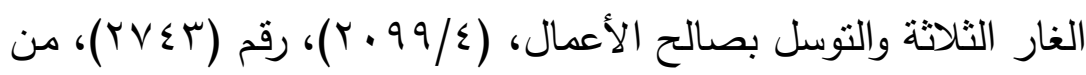
حديث ابن عمر رضي الله تعالى عنهما. r. البخاري كتاب: أبواب الاستسقاء، باب: سؤال الناس الإمام الاستسقاء

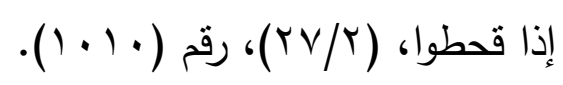

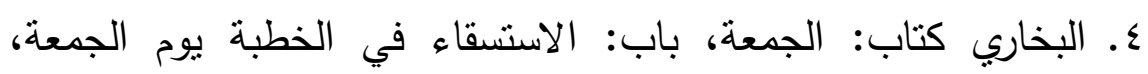

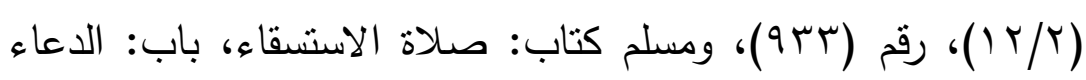

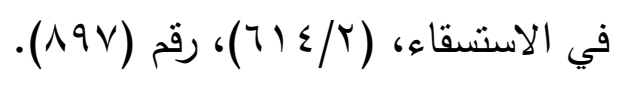

ه. التبالي ، العسبري ، النجدي (المتوفى: 9 ؟ اهـ) الدحقق: عبد السلام

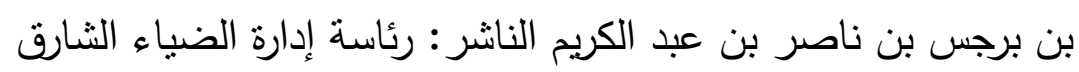

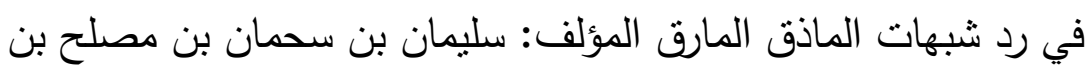

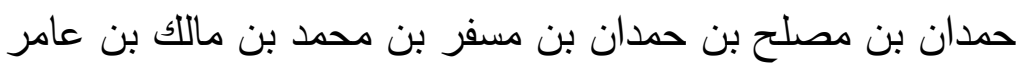
الختعمي. (بلا تاريخ). 


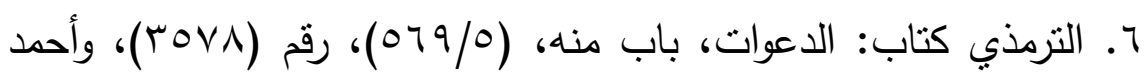

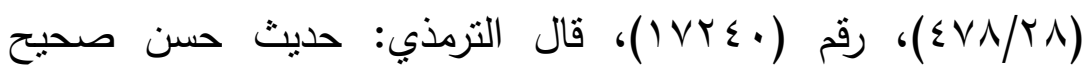

V. التبيبه والرد على أهل الأهواء المؤلف: محمد بن أحمد بن عبد الرحمن،

أبو الحسين المَلَطي العسقلاني (المتوفى: لو

المكتبة الأزهرية للتراث - مصر، المحقق: محمد زاهد بن الحسن

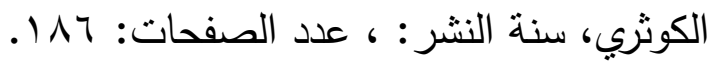

^. التوسل أنواعه وأحكامه المؤلف: أبو عبد الرحمن محمد ناصر الدين،

بن الحاج نوح بن نجاتي بن آدم، الأشقودري الألباني (المتوفى: • .

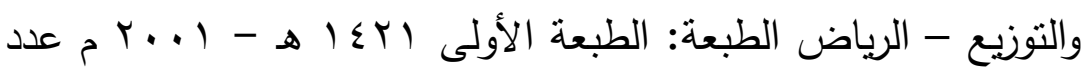
الصفحات:

9 ـ الصواعق المحرقة على أهل الرفض والضلص والزندقة ، ابن حجر

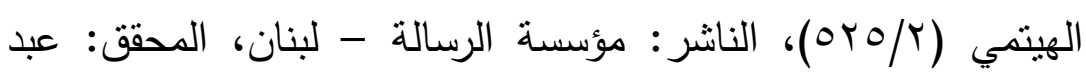
الرحمن بن عبد الله التركي - كامل محمد الخراط، الطبعة: الأولى، لهـ

$$
\text { . } 199 \mathrm{~V}-81 \leq 1 \mathrm{P}
$$

• ا. الضياء الثارق في رد شبهات الماذق المارق المؤلف: سليمان بن سحمان بن مصلح بن حمدان بن مصلح بن حمدان بن مسفر بن محمد بن ماللك بن عامر الخثعدي ، التبالي ، العسيري ، النجدي (المتوفى: q § إه) المحقق: عبد السلام بن برجس بن ناصر بن عبد الكريم الناشر: رئاسة إدارة البحوث العلمية والإفتاء، الرياض، المملكة العربية

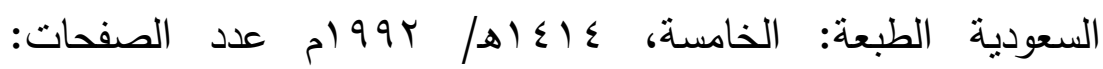
$\varepsilon 9 \leq \operatorname{c|9}$ 
11. الكثاف عن حقائق غوامض التنزيل (مع الكتاب حاشية (الانتصاف فيما تضمنه الكثاف) لابن المنير الإسكندري (ت r/T)، وتخريج أحاديث الكثاف للإمام الزيلعى) المؤلف: أبو القاسم محمود بن عمرو بن أحمد، الزمخشري جار الله (المتوفى: ^بهـه) الناشر: دار الكتاب العربي بيروت. (بلا تاربخ).

r ا. بيان تلبيس الجهمية (ع/YVT)، الناشر: مجمع الملك فهر لطباعة المصحف الشريف، المحقق: مجموعة من المحققين، الطبعة: الأولى، דץ § (هـ، عدد الأجزاء: · . . (بلا تاريخ).

با ـ ـ تأسيس التقديس في كثف ثلبيس داود بن جرجيس المؤلف: عبد الله بن عبد الرحمن بن عبد العزيز بن عبد الرحمن بن عبد اله بن سلطان بن

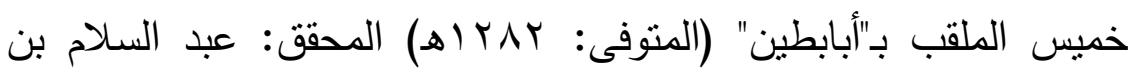
برجس العبد الكريم الناشر: مؤسسة الرسالة الطبعة: الطبعة الأولى به به

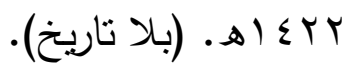
ع ا. . تخجيل من حرف التوراة والإنجيل (Y)/Y)، الناشر : مكتبة العبيكان، الرياض، المملكة العربية السعودية، المحقق : محمود عبد الرحمن قدح،

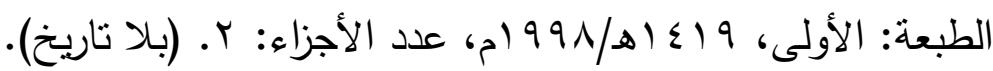
1. ـ تفسير كلام المنان المؤلف: عبد الرحمن بن ناصر بن عبد الله السعدي

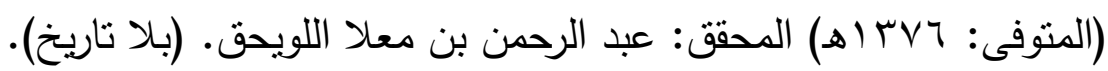
7 ا. تهذيب اللغة المؤلف: محمد بن أحمد بن الأزهري الهروي، أبو منصور (المتوفى: • • آهـ) المحقق: محمد عوض مرعب الناشر : دار إحياء التراث العربي - بيروت الطبعة: الأولى، ا . . rم عدد الأجزاء: ^. (بلا تاربخ). 
V ا. تيسير العزيز الحميد في شرح كتاب التوحيد (ص اء؟)، الناشر: المكتب الاسلامي، بيروت، دمشق، المحقق: زهير الثشاويش، الطبعة:

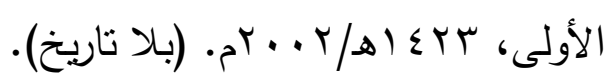

1 1. جلاء العينين في محاكمة الأحمدين المؤلف: نعمان بن محمود بن عبد الله، أبو البركات خير الدين، الآلوسي (المتوفى: VI Vاهـ) قدم له: علي السيد صبح المدني - رحمه الله - الناشر: مطبعة المدني عام النشر:

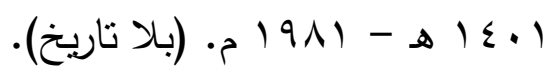

9 1. فصل التاء، مادة [وسيلة]، الناشر: المكتبة العصرية - الدار النموذجية، بيروت - صيدا، المحقق: يوسف الثيخ محمد، الطبعة: الخامسة،

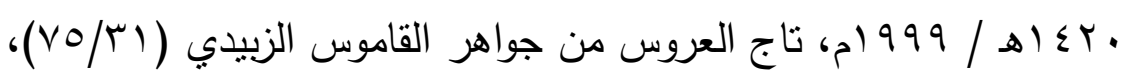
فصل التاء، مادة [وسيلة]، الناشر: دار الهداي مختار الصحاح الرازي

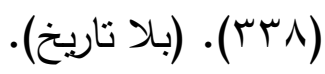

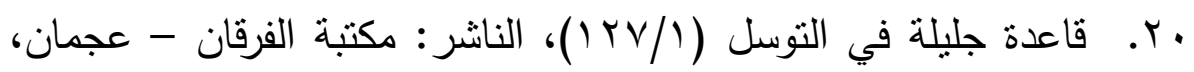
المحقق: ربيع بن هادي عمير المدخلي، الطبعة: الأولى (لمكتبة الفرقان)

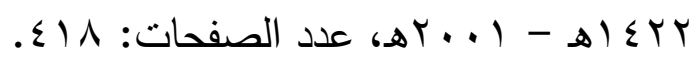
ا r. كتاب قاعدة جليلة في التوسل والوسيلة المؤلف: تقي الدين أبو العباس أحمد بن عبد الحليم بن عبد السلام بن عبد الله بن أبي القاسم بن محمد

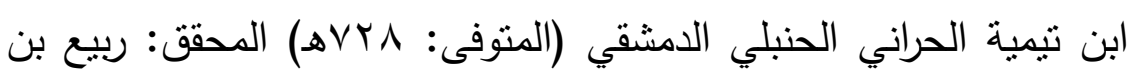
هادي عمير المدخلي الناشر: مكتبة الفرقان - عجمان الطبعة: الأولى

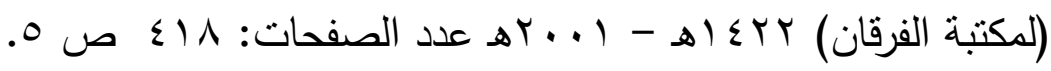
r. r. مجموع الفتاوى المؤلف: تقي الدين أبو العباس أحمد بن عبد الحليم بن

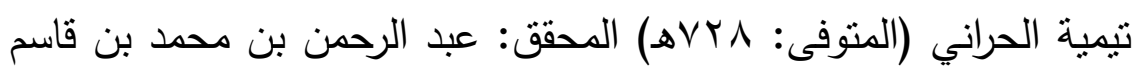
الناشر: مجمع الملك فهد لطباعة المصحف الثريف، المدينة النبوية، 


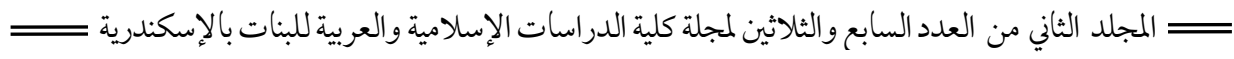

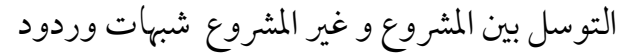

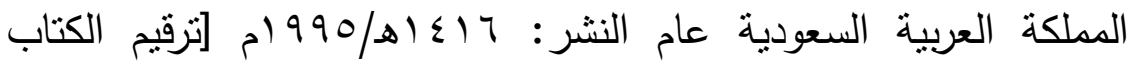
موافق للمطبوع] ، نشر: دار أضواء السلف، الطبعة الأولى: بrی

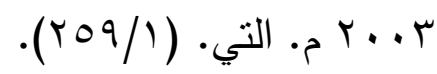

rr. م مفاتيح الغيب = التفسير الكبير المؤلف: أبو عبد الله محمد بن عمر بن الحسن بن الحسين التيمي الرازي الملقب بفخر الدين الرازي خطيب الري (المتوفى: 7 ـ 7 هـ) الناشر : دار إحياء التراث العربي - بيروت الطبعة:

$$
\text { الثالثة - . ب 1 أهـ . (بلا تاريخ). }
$$




\section{فهرس الآيات الكريمة}

\begin{tabular}{|c|c|}
\hline السورة & الآية \\
\hline سورة الاسراء آية vo & 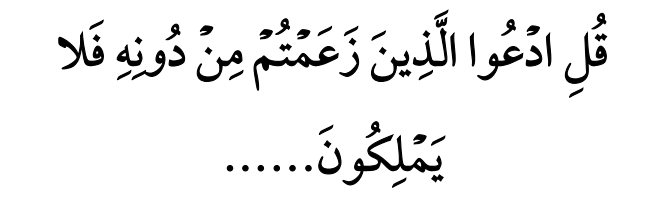 \\
\hline سورة الأنعام آية V & وَإِن يمسسك الله بضر........ \\
\hline سورة الأعراف آية 1 1 & ولله الأسحاء الحسنىل............. \\
\hline سورة هود آية 1 ـ 1 & 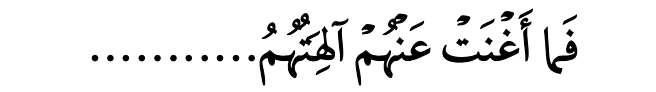 \\
\hline سورة السجدة آية ؛ & 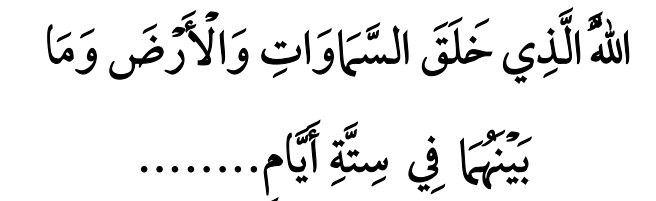 \\
\hline سورة الثعراء آية ؟ 9 - & 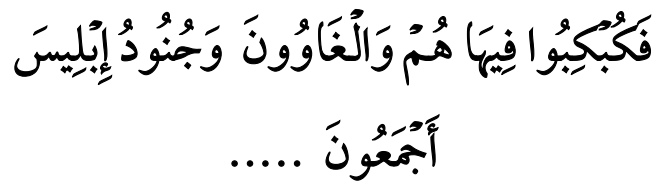 \\
\hline سورة يونس V V V & 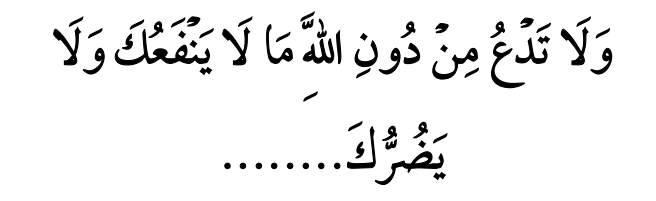 \\
\hline
\end{tabular}




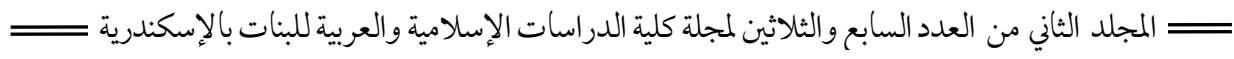

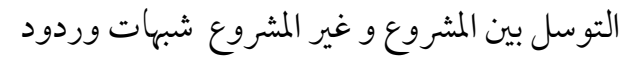

\section{References}

1. aqtida' alsirat almustaqim limukhalafat 'ashab aljahim limualifin: taqi aldiyn 'abu aleabaas 'ahmad bin eabd alhalim bin eabd alsalam bin eabd allah bin 'abi alqasim bin muhamad aibn taymiat alharaanii alhanbali aldimashqii (almutawafaa: 728hi) almuhaqiqi: nasir eabd alkarim aleaql alnaashir: dar ealam alkutab, bayrut, lubnan altabeata: alsaabieati, 1419h - 1999m eadad al'ajza'i: 2 (2/318).

2. albukhariu kitabi: al'iijarati, babi: man astajar 'ajirana fatarak al'ajir 'ajrahu, faeamil fih almustajir fazada, 'aw min eamil fi mal ghayrihi, fastafdala, (3/91), raqm (2272), wamuslim kitabi: alraqaqi, bab: qisat 'ashab alghar althalathat waltawasul bisalih al'aemali, (4/2099), raqm (2743), min hadith abn eumar radi allah taealaa eanhuma.

3. albukhari kitabu: 'abwab aliastisqa'i, bab: suaal alnaas al'iimam aliastisqa' 'iidha qahtua, (2/27), raqm (1010).

4. albukhariu kitabi: aljumeati, bab: aliastisqa' fi alkhutbat yawm aljumeati, (2/12), raqm (933), wamuslim kitabi: salat aliastisqa'i, bab: alduea' fi aliastisqa', (2/614), raqm (897).

5. altabali , aleasiri, alnajdi (almutawafaa: 1349hi) almuhaqiq: eabd alsalam bin birjas bin nasir bin eabd alkarim alnaashir: riasat 'iidarat aldiya' alshaariq fi radi shubhat almadhiq almariq almualafi: sulayman bin sahman bin maslah bin hamdan bin maslah bin hamdan bin misfar bin muhamad bin malik bin eamir alkhatheami. (bila tarikhin). 


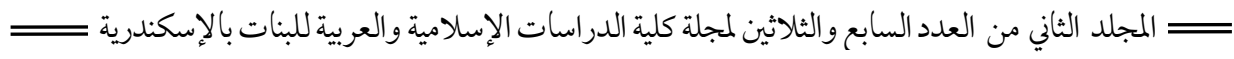

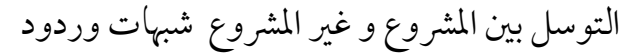

6. altirmidhiu kitabi: aldaeawati, bab minhu, (5/569), raqm (3578), wa'ahmad (28/478), raqm (17240), qal altirmidhi: hadith hasan sahih ghirib.

7. altanbih walradu ealaa 'ahl al'ahwa' almualafi: muhamad bin 'ahmad bin eabd alrahman, 'abu alhusayn almalaty aleasqalanii (almutawafaa: 377hi) (s 99), alnaashir: almaktabat al'azhariat lilturath - masir, almuhaqaqa: muhamad zahid bin alhasan alkuthari, sanat alnashri: , eadad alsafahati: 186.

8. altawasul 'anwaeuh wa'ahkamuh almualafu: 'abu eabd alrahman muhamad nasir aldiyn, bin alhaj nuh bin najati bin adim, al'ushqudri al'albaniu (almutawafaa: 1420hi) almuhaqaqa: muhamad eid aleabaasi alnaashir: maktabat almaearif lilnashr waltawzie - alriyad altabeatu: altabeat al'uwlaa 1421 hi - $2001 \mathrm{~m}$ eadad alsafahati: $154 \mathrm{~s} 70$.

9. alsawaeiq almihraqat ealaa 'ahl alrafd waldalal walzandaqat, aibn hajar alhaytmii (2/525), alnaashir: muasasat alrisalat - lubnan, almuhaqiq: eabd alrahman bin eabd allah alturki - kamil muhamad alkharati, altabeata: al'uwlaa, 1417h - 1997m.

10. aldiya' alshaariq fi radi shubhat almadhiq almariq almualafi: sulayman bin sahman bin maslah bin hamdan bin maslah bin hamdan bin misfar bin muhamad bin malik bin eamir alkhatheamii , altabali , aleasirii , alnajdii (almutawafaa: 1349hi) almuhaqiq: eabd alsalam bin birjis bin nasir bin eabd alkarim alnaashir: riasat 'iidarat albuhuth aleilmiat wal'iifta', alrayada, almamlakat alearabiat alsaeudiat altabeati: alkhamisati, 1414hi/ 1992m eadad alsafahati: 690sa494 


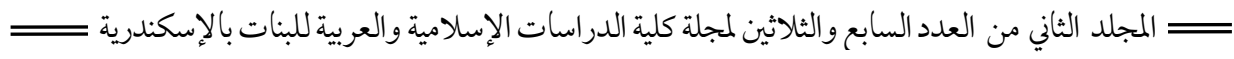

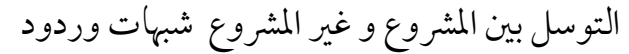

11. alkashaf ean haqayiq ghawamid altanzil (mae alkitaab hashiatan (alaintisaf fima tadamanah alkashafu) liaibn almunir al'iiskandari (t 683), watakhrij 'ahadith alkishaf lil'iimam alziylieaa) almualafu: 'abu alqasim mahmud bin eamriw bin 'ahmad, alzamakhashari jar allah (almutawafaa: 538hi) alnaashir: dar alkitaab alearabii bayrut. (bla tarikhin).

12. byan talbis aljihmia (4/376), alnaashir: majamae almalik fahd litibaeat almushaf alsharifi, almuhaqaqi: majmueat min almuhaqiqina, altabeata: al'uwlaa, 1426hi, eadad al'ajza'i: 10. (bila tarikhin).

13. tasis altaqdis fi kashf talbis dawud bin jirjis almualafa: eabd allah bin eabd alrahman bin eabd aleaziz bin eabd alrahman bin eabd allh bin sultan bin khamis almulaqab bi"'ababtin" (almutawafaa: 1282hi) almuhaqiq: eabd alsalam bin birjis aleabd alkarim alnaashir: muasasat alrisalat altabeati: altabeat al'uwlaa $1422 \mathrm{~h}$. (bla tarikhin).

14. takhjil min harf altawrat wal'iinjil (2/741), alnaashir: maktabat aleibikan, alrayad, almamlakat alearabiat alsaeudiat, almuhaqaq : mahmud eabd alrahman qadaha, altabeata: al'uwlaa, 1419h/1998m, eadad al'ajza'i: 2. (bila tarikhin).

15. tafsir kalam aalminan almualafa: eabd alrahman bin nasir bin eabd allah alsaedi (almutawafaa: 1376hi) almuhaqiqa: eabd alrahman bin maeala alluwayahaqi. (bila tarikhin).

16. tahdhib allughat almualafi: muhamad bin 'ahmad bin al'azharii alhurawi, 'abu mansur (almutawafaa: 370hi) almuhaqaqi: muhamad eawad mureib alnaashir: dar 'iihya' alturath alearabii - 


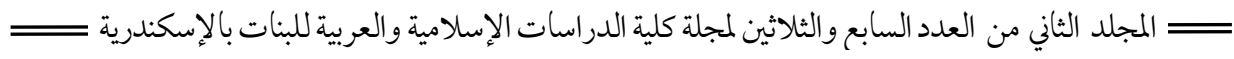

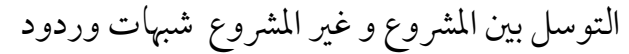

bayrut altabeatu: al'uwlaa, $2001 \mathrm{~m}$ eadad al'ajza'i: 8. (bila tarikhin).

17. taysir aleaziz alhamid fi sharh kitab altawhid (s 241), alnaashiru: almaktab alaslamia, bayrut, dimashqa, almuhaqaqi: zuhayr alshaawish, altabeatu: al'uwlaa, 1423h/2002m. (bla tarikhin).

18. jala' aleaynayn fi muhakamat al'ahmadin almualafi: nueman bin mahmud bin eabd allah, 'abu albarakat khayr aldiyn, alalusi (almutawafaa: 1317hi) qadim lah: eali alsayid subh almadanii rahimah allah - alnaashir: matbaeat almadanii eam alnashri: 1401 hi - 1981 mi. (bla tarikhin).

19. fasal altaa', mada [wasila], alnaashir: almaktabat aleasriat - aldaar alnamudhajiatu, bayrut - sayda, almuhaqiqa: yusif alshaykh muhamad, altabeata: alkhamisatu, 1420h / 1999m, taj alearus min jawahir alqamus alzubaydii (31/75), fasl altaa', mada [wasilata], alnaashir: dar alhaday mukhtar alsihah alraazi (338). (bila tarikhin).

20. qaeidat jalilat fi altawasul $(1 / \Lambda$ $/$ ), alnaashir: maktabat alfurqan - eajman, almuhaqiqu: rabie bin hadi eumayr almadkhali, altabeatu: al'uwlaa (limaktabat alfirqan) $\backslash \leqslant r$ rh $-r \cdots \backslash$ hi, eadad alsafahati: $\ \wedge$.

21. ktab qaeidat jalilat fi altawasul walwasilat almualafi: taqi aldiyn 'abu aleabaas 'ahmad bin eabd alhalim bin eabd alsalam bin eabd allah bin 'abi alqasim bin muhamad aibn taymiat alharaanii alhanbali aldimashqii (almutawafaa: $\vee r \wedge$ hi) almuhaqiqi: rabie bin hadi eumayr almadkhali alnaashir: maktabat 
alfurqan - eajman altabeatu: al'uwlaa (limaktabat alfirqan) $1422 \mathrm{~h}-2001 \mathrm{hu}$ eadad alsafahati: $418 \mathrm{~s} 5$.

22. majmue alfatawaa almualafi: taqi aldiyn 'abu aleabaas 'ahmad bin eabd alhalim bin taymiat alharaani (almutawafaa: 728hi) almuhaqiq: eabd alrahman bin muhamad bin qasim alnaashir: majmae almalik fahd litibaeat almushaf alsharifi, almadinat alnabawiati, almamlakat alearabiat alsueudiat eam alnashri: 1416hi/1995m [tarqim alkitab muafiq lilmatbuea] , nashra: dar 'adwa' alsalaf, altabeat al'uwlaa: $1423 \mathrm{hi} / 2003 \mathrm{mi}$. alti. (1/259).

23. mafatih alghayb = altafsir alkabir almualafu: 'abu eabd allah muhamad bin eumar bin alhasan bin alhusayn altaymi alraazi almulaqab bifakhr aldiyn alraazii khatib alrayi (almutawafaa: 606hi) alnaashir: dar 'iihya' alturath alearabii - bayrut altabeata: althaalithat - 1420 hi. (bila tarikhin). 